\title{
An Eye on the Dog as the Scientist's Best Friend for Translational Research in Ophthalmology: Focus on the Ocular Surface
}

\author{
Lionel Sebbag ${ }^{1,2}$ and Jonathan P. Mochel ${ }^{1}$ \\ ${ }^{1}$ Department of Biomedical Sciences, SMART Pharmacology; ${ }^{2}$ Department of Veterinary Clinical \\ Sciences, College of Veterinary Medicine, Iowa State University, Ames, IA 50011, USA
}

\begin{abstract}
Preclinical animal studies provide valuable opportunities to better understand human diseases and contribute to major advances in medicine. This review provides a comprehensive overview of ocular parameters in humans and selected animals, with a focus on the ocular surface, detailing species differences in ocular surface anatomy, physiology, tear film dynamics and tear film composition. We describe major pitfalls that tremendously limit the translational potential of traditional laboratory animals (ie., rabbits, mice and rats) in ophthalmic research, and highlight the benefits of integrating companion dogs with clinical analogues to human diseases into preclinical pharmacology studies.

This One Health approach can help accelerate and improve the framework in which ophthalmic research is translated to the human clinic. Studies can be conducted in canine subjects with naturally occurring or noninvasively induced ocular surface disorders (eg., dry eye disease, conjunctivitis), reviewed herein, and tear fluid can be easily retrieved from canine eyes for various bioanalytical purposes. In this review, we discuss common tear collection methods, including capillary tubes and Schirmer tear strips, and provide guidelines for tear sampling and extraction to improve the reliability of analyte quantification (drugs, proteins, others).
\end{abstract}

Key words: Ocular Surface, Tear Film, Albumin, Pharmacology, Animal models, Translational Research, One Health

\section{Correspondence:}

Lionel Sebbag, DVM, Dipl. ACVO

lsebbag@iastate.edu

Jonathan P Mochel, DVM, MS, PhD, Dipl. ECVPT

jmochel@iastate.edu 


\section{Introduction}

Preclinical animal models provide critical information to better understand human diseases' characteristics, identify biomarkers, develop diagnostic tools and novel therapeutics. Rabbits and laboratory rodents (mice, rats) are widely used for ophthalmic research as they are economical and easy to handle; ${ }^{1}$ however, serious drawbacks limit the translational usefulness of data obtained in these species, notably due to the need to artificially induce pathology in these animals (eg., through genetic manipulation or experimental surgery), as well as apparent differences in ocular anatomy and physiology compared to humans. For instance, precorneal residence time of topically applied solutions is much prolonged in rabbits owing to their low blink rate, resulting in 3-fold overestimation of ocular drug exposure if findings were directly extrapolated from rabbits to humans. ${ }^{2}$ Another example is topical nepafenac, a potent nonsteroidal anti-inflammatory drug (NSAID) that reaches therapeutic levels in the posterior segment of mice (owing to their thin cornea and small globe size), inhibiting choroidal neovascularization by decreasing production of VEGF $^{3}-$ in contrast, humans require intravitreal injections of anti-VEGF compounds to achieve the same outcome. Multiple other examples exist in the scientific literature, together participating to the unacceptably low success rate of ophthalmic clinical trials to date, and resulting in substantial economic loss and burden for scientists, consumers, and society overall. ${ }^{4}$ In fact, the main cause for clinical trial failure is either lack of safety or efficacy, ${ }^{5}$ two components that are supposedly 'validated' in initial preclinical animal studies.

Under the umbrella of the One Health Initiative, a growing number of investigations have integrated companion animals into preclinical studies to complement and expand the knowledge gained from studies in other animal models, accelerate and improve the framework in which research is translated to the human clinic, and ultimately generate discoveries that will benefit the health of humans and animals. ${ }^{6}$ Over the last few years, several review articles have highlighted the benefits of using dogs for translational research in oncology, ${ }^{7}$ neurology ${ }^{8}$ and other biomedical fields, ${ }^{6}$ yet such information is not available in ophthalmology.

The present review provides a comprehensive comparison of key ocular parameters in humans, dogs and traditional laboratory animals (ie., rabbits, mice, rats), highlighting selected strengths and important pitfalls that must be addressed when ocular research is conducted in animal models. This review is focusing on the ocular surface, a critical element of vision that includes the secreted tear film, lacrimal gland(s), eyelids, meibomian glands, cornea, conjunctiva, sclera, and nasolacrimal drainage apparatus. The ocular surface dictates the bioavailability of medications administered topically to the eye, ${ }^{9}$ and is a common site of pathology in both human and veterinary medicine. Methods of tear fluid collection for bioanalytical purposes are also being discussed, with special consideration on the safety and efficiency of the collection technique at hand. Lastly, this review highlights on spontaneous and experimental ocular surface disorders in dogs, providing a tool for researchers to better model disease pathophysiology in clinical patients suffering from ocular surface disorders.

\section{Comparative anatomy and physiology of the ocular surface}

\subsection{Anatomy}

The anatomy of the ocular surface is depicted in Figure 1 for dogs, and its parameters are being summarized in Table 1 for all species discussed in this review (ie., humans, dogs, rabbits, mice, rats). 
Lacrimal glands - Four types of lacrimal glands can be distinguished in mammals: (i) the orbital lacrimal gland (glandulae lacrimales superior), located in the dorsolateral orbit just caudal to the orbital rim, with secretory ducts that open into the upper conjunctival fornix (humans, dogs, rabbits); (ii) the gland of the third eyelid, located in the ventromedial orbit at the base of the nictitating membrane with secretory ducts than open into the nictitans' bulbar conjunctiva (dogs); (iii) the infraorbital gland (glandulae lacrimales inferior), located either intraorbital and ventromedial to the globe (rabbits) or extraorbital and caudal to the globe (rodents), with a single secretory duct that opens into the lower conjunctival fornix; and (iv) the Harderian gland, or Harder's gland, extending from the base of the third eyelid into the caudal orbit, with secretory ducts opening at the nictitating membrane (rabbits, rodents). ${ }^{10,11}$ The histomorphology of lacrimal glands varies with age and sex of the individual. ${ }^{12}$ In dogs, an orbital lacrimal gland and gland of the third eyelid contribute to $60-70 \%$ and $30-40 \%$ of the overall tear secretion, respectively. ${ }^{13}$ The morphological and histological features of the canine glands resemble the human lacrimal gland including distinct lobules and acini that provide serous and mucous secretions, as well as intralobular ducts that drain into small excretory tubules. ${ }^{14,15}$ Likewise, an Harderian gland is not present in the canine or human orbit. ${ }^{14-16}$ However, two notable differences exist between species: (i) the combined volume of the two canine glands is smaller than the main lacrimal gland in humans $\left(0.24 \mathrm{vs} .0 .60 \mathrm{~cm}^{2}\right)^{17,18}$; and (ii) the accessory lacrimal glands of Krause and Wolfring are absent in dogs (or not yet reported), presumably being consolidated through evolution into the single gland of the third eyelid. ${ }^{19}$ These accessory glands account for $10 \%$ of the total lacrimal secretory mass in humans but their contribution to the overall tear secretion is negligible (1$2 \%){ }^{20,21}$ In rabbits, the histoarchitecture of the main lacrimal gland is comparable to humans with loosely packed acini and round/oval lumen; in contrast, mice and rats have densely packed acini with small pleiomorphic lumen and numerous intercellular tight junctions. ${ }^{22}$ Like humans, rabbits also possess accessory lacrimal glands of Wolfring in the tarsal portion of the palpebral conjunctiva. ${ }^{23}$ However, the Harderian gland present in rabbits and rodents is a unique anatomical feature that has important repercussions for comparative studies; in fact, the gland's lipid secretions in the tear film have profound effects on the ocular surface physiology (eg., tear composition, tear film dynamics, blink rate) and pharmacology of topically applied medications (see sections 2.2 and 2.3).

Nasolacrimal apparatus - The morphology of the canine lacrimal drainage system is remarkably similar to that of humans, except for a longer nasolacrimal duct (notably in long-nosed dogs), and the presence of accessory duct openings into the nasal cavity. ${ }^{24}$ In both species, tear drainage begins with the lower and upper nasolacrimal puncta and canaliculi in the medial canthus, joining into a lacrimal sac in the bony lacrimal fossa, and extending into the nasolacrimal duct that runs through an osseous channel towards the nasal cavity. ${ }^{25}$ Species similarities are also evident on a microscopic level, including an epithelial lining with microvilli and mucin-secreting goblet cells, sub-epithelial seromucous glands, and mucosal-associated lymphoid tissue. ${ }^{24}$ In contrast, the nasolacrimal apparatus of rabbits has distinct differences compared to humans. Rabbits only have a single nasolacrimal punctum/canaliculus (medial lower eyelid) and the nasolacrimal duct has two very distinct flexures due to the ventral deflection of the snout, a unique feature that results in a convoluted path for tear drainage. ${ }^{25,26}$ The fetal development of the rabbit's nasolacrimal apparatus is also unique in mammals, more closely resembling reptiles vs. humans. ${ }^{27}$ At an ultrastructural level, the epithelium lining the duct is double-layered (similar to humans) but there are no goblet cells or subepithelial seromucous glands. ${ }^{28}$ Nonetheless, the use of the rabbit is still recommended as a practical model to characterize the nasolacrimal apparatus, ${ }^{29}$ albeit this choice is described as 'less than ideal' by the 
authors. Mice and rats have a well-developed nasolacrimal apparatus that shares similar ontogenetic origin to humans, ${ }^{27}$ although the histological features are different. The duct lining is covered by a multi-layered stratified squamous epithelium with goblet cells but without sub-epithelial seromucous glands. ${ }^{25}$

Third eyelid - The nictitating membrane (third eyelid) is a large fold of the conjunctiva that protrudes from the medial canthus over the anterior surface of the globe in many animals, including dogs, rabbits and rodents. The counterpart in humans is the plica semilunaris, a vestigial remnant in the form of a crescentlike conjunctival fold in the medial canthus. ${ }^{11,30}$ Despite gross differences, both structures have important physio-morphological similarities such as the presence of goblet cells and lymphoid follicles, contributing to the lubrication and immune protection of the ocular surface..$^{30}$ Nonetheless, the presence of a third eyelid should be considered in comparative studies as it could impact ocular examinations (eg., third eyelid protrusion from ocular irritation) or ocular drug delivery (eg., altered retention time of a contact lens), ${ }^{31}$ among others. If required for ease of experimentation, a simple fixation of the nictitating membrane can be performed $^{31}$ as an alternative to complete surgical removal, ${ }^{13,32,33}$ as the latter negatively impacts ocular surface homeostasis. ${ }^{13,34}$

Eyelids - Similar to humans, the canine upper and lower eyelids are comprised of an outer dermis, tarsus, orbicularis oculi muscle, palpebral conjunctiva and secretory tissues including meibomian glands (20-40 per eyelid), glands of Zeis and Moll. ${ }^{35,36}$ The main anatomical difference is the tarsal plate, which is comprised of dense fibrous tissue and cartilage-specific components in humans ${ }^{37}$ - providing a rigid internal support to the eyelids - compared to a much thinner and poorly-developed fibrous tissue in dogs. ${ }^{38}$ Also, the interpalpebral fissure area is approximately $20 \%$ larger in dogs $\left(2.2 \mathrm{vs} .1 .8 \mathrm{~cm}^{2}\right)^{39,40}$, although the measurements of the palpebral fissure width depend on the dog's size and body weight. ${ }^{40}$

The palpebral opening in the rabbit is relatively small $(10-16 \mathrm{~mm}),{ }^{38,41,42}$ albeit much larger than mice (3.7$5 \mathrm{~mm})^{43}$ and rats $(6-9 \mathrm{~mm})^{44,45}$, with a shorter and thicker upper eyelid compared to the inferior palpebrae; consequently, the interpalpebral fissure area is $20 \%$ smaller in rabbits than in man $\left(1.44 \mathrm{vs} .1 .8 \mathrm{~cm}^{2}\right) .{ }^{39}$ The meibomian gland ducts and acini are also larger in rabbits than mice and rats, ${ }^{46}$ but the overall volume and distribution of meibomian glands is different than in humans: the total meibomian gland volume in the human $\left(39.5 \mathrm{~mm}^{3}\right)$ is twice that of the rabbit $\left(18.8 \mathrm{~mm}^{3}\right)$, with a larger volume in the upper eyelid (man) compared to similar volumes in the upper and lower eyelids (rabbit). ${ }^{39}$

Conjunctiva - The conjunctiva is a thin mucous membrane that serves important roles on the ocular surface including mucin secretion and immune surveillance. The anatomical subdivision of the conjunctiva is the same in humans, dogs, and common laboratory species (rabbits, rodents): the palpebral conjunctiva - lining the inside of the eyelids - reflects back at the level of the conjunctival fornix to form the bulbar conjunctiva, a region that covers the anterior portion of the sclera and attaches to the corneoscleral limbus. ${ }^{16}$ However, the amount of bulbar conjunctiva exposed ('scleral show') is notably larger in humans compared to animals given differences in eyelid opening and/or corneal diameter. Another important species difference is the presence of a nictitating membrane in animals (but not man), as the third eyelid is covered by conjunctiva on its anterior and posterior surfaces. As such, animals have two conjunctival fornices in the inferonasal region - one on each side of the third eyelid - and the overall conjunctival surface is generally larger in animals compared to humans. In dogs, the conjunctival area is supposedly larger than in humans given the depth of the canine conjunctival fornices and the amount of conjunctiva covering the canine nictitating membrane, ${ }^{47}$ although no objective data exist to date. In rabbits, the upper conjunctival fornix depth (20.36 $\mathrm{mm})^{48}$ is larger than in humans $(15 \mathrm{~mm}),{ }^{49}$ while the conjunctival area is reportedly comparable (13.34- 
18.48 vs. $17.65 \mathrm{~cm}^{2}$, respectively), although the measurements did not include the rabbit's third eyelid (surgically removed by investigators). ${ }^{50}$

Conjunctival goblet cells are distributed individually in humans, dogs and rabbits, in contrast to clustered organization in mice and rats. ${ }^{51,52}$ The distribution of goblet cells is overall similar in dogs and humans, with high density in the canine third eyelid and human plica semilunaris, relatively high density in the conjunctival fornices and palpebral conjunctiva, and lower density in the bulbar conjunctiva. ${ }^{30,52-56}$ In rabbits, the highest density is noted at the lid margin of both upper and lower palpebral conjunctivae, ${ }^{57,58}$ while the density in the bulbar conjunctiva is generally higher than in humans $\left(399-1576 \mathrm{cells} / \mathrm{mm}^{2}\right.$ vs. 7979 cells $\left./ \mathrm{mm}^{2}\right) .{ }^{56,59}$ In addition to mucin-secreting goblet cells, the conjunctiva also contains an organized immune network termed conjunctiva-associated lymphoid tissue (CALT), a structure that plays a key role in protecting the ocular surface by initiating and regulating immune responses. ${ }^{60}$ The presence of lymphoid follicles was confirmed in the conjunctiva of most mammals studied by Chodosh and colleagues - including humans, dogs, rabbits - with the exception of mice and rats, ${ }^{61}$ although a later report detected lymphoid tissue in the nictitating membrane of BALB/c mice. ${ }^{62}$ At an ultrastructural level, specialized $\mathrm{M}$ cells are present in the epithelium overlying the conjunctival follicles in $\operatorname{dogs}^{63}$ and rabbits, ${ }^{64}$ similar to humans. ${ }^{65}$

Cornea - The anatomy of the cornea is unique to each species with important differences in corneal dimensions and ultrastructural features (eg., thickness, collagen arrangement, nerve supply). ${ }^{11,38,50,66-70}$ First, the cornea is generally larger in dogs and rabbits compared to humans, while the dimensions are much smaller in mice and rats. ${ }^{41,44,71-77}$ As such, the relative amount of cornea and conjunctiva exposed on the ocular surface varies among species, an anatomical fact that has important implications in ocular pharmacology and other research fields; for instance, the surface area ratio of conjunctiva to cornea is two times smaller in rabbits (8.6-8.9) than humans (17.1), a finding that could largely explain species differences in drug penetration into the anterior chamber. ${ }^{50}$ Second, the corneal thickness varies among mammals and is generally correlated to the size of the animal. ${ }^{68}$ From highest to lowest, the mean central corneal thickness is 497-594 $\mu \mathrm{m}$ in dogs, ${ }^{68,78} 505-563 \mu \mathrm{m}$ in humans, ${ }^{79} 354-407 \mu \mathrm{m}$ in rabbits, ${ }^{41,79,80} 159-170 \mu \mathrm{m}$ in rats ${ }^{68,80}$ and $90-137 \mu \mathrm{m}$ in mice. ${ }^{68,74,80}$ The average canine cornea is only slightly thicker than in humans. In contrast, the thinner cornea in rabbits and rodents can limit the use of these laboratory species for selected experiments; for instance, cross-linking is discouraged in corneas thinner than $400 \mu \mathrm{m}$ due to potential damage to the corneal endothelium or intraocular tissues. ${ }^{81}$

On a structural level, the main layers of the cornea are the same in humans and animals (epithelium, stroma, Descemet membrane, endothelium) with the notable exception of the Bowman's membrane. ${ }^{11,70}$ Bowman's membrane is present in nearly all primates (including humans) and selected animals (eg., sheep, deer, giraffe), ${ }^{82}$ but is absent in dogs and common laboratory species. ${ }^{68,70,82}$ The number of layers and overall thickness of the corneal epithelium vary among species: humans (5-7 layers, 44-55 $\mu \mathrm{m}),{ }^{79,83} \operatorname{dogs}(6-9$ layers, 52-64 $\mu \mathrm{m}),{ }^{70,71,78}$ rabbits (5-7 layers, 45-49 $\left.\mu \mathrm{m}\right),{ }^{38,79,83}$ rats (10-14 layers, 26-33 $\left.\mu \mathrm{m}\right),{ }^{84,85}$ and mice (13 layers, $37-46 \mu \mathrm{m}){ }^{74}$ The corneal stroma, comprising nearly $90 \%$ of the total corneal thickness in most mammals, is primarily composed of collagen fibrils arranged in lamellae. While extensive collagen intertwining is noted in the majority of the corneal stroma in humans, it is only present in the anterior mostaspect of the cornea in dogs and rabbits. ${ }^{86,87}$ Differences in collagen intertwining, along with the absence of Bowman's membrane in laboratory species, explain the vast disparity in stiffness of the anterior stroma $(16.2,1.3$ and $1.1 \mathrm{kPa})$ and posterior stroma $(2.5,0.5$ and $0.4 \mathrm{kPa})$ in humans, dogs and rabbits, respectively. ${ }^{86,87}$ The elastic modulus of the cornea is reportedly higher in rodents, although the methodology used was different. ${ }^{88,89}$ Corneal rigidity should be considered in comparative studies in which 
the biophysical attributes of the cornea are important (eg., wound healing, keratoprosthesis). The corneal endothelium shares a similar morphological blueprint among species (single cell layer, honey-comb pattern), while the cellular density varies from $3233 \mathrm{cells} / \mathrm{mm}^{2}$ in rabbits, $2875 \mathrm{cells} / \mathrm{mm}^{2}$ in mice, 2818 cells $/ \mathrm{mm}^{2}$ in dogs, 2732 cells $/ \mathrm{mm}^{2}$ in humans, and 2242 cells $/ \mathrm{mm}^{2}$ in rats. ${ }^{68,90}$

The mammal cornea is the most densely innervated tissue in the body. Corneal nerves play important roles to maintain ocular surface health and homeostasis, including sensory functions (touch, pain, temperature), release of trophic neuropeptides, maintenance of the limbal stem cell niche, and activation of brainstem circuits to promote reflex blinking and lacrimation. From highest to lowest, the sensitivity of the cornea to mechanical stimulus is as follows: humans $\left(0.2-1.0 \mathrm{~g} / \mathrm{mm}^{2}\right)$, rats $\left(0.42-0.47 \mathrm{~g} / \mathrm{mm}^{2}\right)$, mice $\left(0.59 \mathrm{~g} / \mathrm{mm}^{2}\right)$, $\operatorname{dogs}\left(2.16-2.9 \mathrm{~g} / \mathrm{mm}^{2}\right)$, and rabbits $\left(6.21-10 \mathrm{~g} / \mathrm{mm}^{2}\right){ }^{2,91-95}$ The murine model is the most extensively studied of all laboratory species given gross similarities between mice and humans in corneal sensitivity and nerve architecture. ${ }^{67,96}$ The canine model is also studied in detail given shared features with humans in several spontaneous diseases such as diabetes mellitus, herpetic keratitis, and non-healing corneal ulcers; ${ }^{97-100}$ importantly, investigators should account for the canine breed selected for the experiment as corneal sensitivity depends on the dog's cephalic conformation. ${ }^{95}$ In regard to rabbits, two striking species differences exist: (i) Corneal sensitivity in rabbits is much lower than in humans, dogs and rodents, ${ }^{2,92}$ and (ii) Morphology of the rabbit subbasal plexus is unique, with nerve fibers sweeping horizontally across the corneal surface in a temporal-to-nasal direction compared to a typical whorl-like or spiraling pattern in other species. ${ }^{67}$

Sclera - Humans have a widely exposed white sclera, a feature that is unique when compared to other primate species (Kobayashi, 1997). In contrast, the scleral exposure is minimal in dogs and routine laboratory species. The thickness of the sclera also differ among species: at the ocular surface (limbal sclera), recorded measurements vary from $0.8 \mathrm{~mm}$ in dogs, ${ }^{101} 0.5 \mathrm{~mm}$ in humans, ${ }^{102} 0.29 \mathrm{~mm}$ in rabbits, ${ }^{103}$ $0.1 \mathrm{~mm}$ or less in rats, ${ }^{104}$ and $0.05-0.06 \mathrm{~mm}$ in mice. ${ }^{105}$

\subsection{Tear film dynamics}

Effective tear dynamics, combined with well-balanced composition of the tear film (discussed in the next section), are critical for the maintenance of ocular surface homesostasis and physiology. Tear fluid dynamics - or the balance between tear secretion, distribution, absorption, evaporation, and drainage - are closely regulated by the lacrimal functional unit. The lacrimal functional unit is unique to each species (see aforementioned anatomical differences), comprised of secreting glands (orbital, accessory, third eyelid, Harder's, meibomian), eyelids, conjunctival goblet cells, corneo-conjunctival surface, and their interconnecting innervation. ${ }^{106}$ Key physiological parameters provide insight into the complex tear dynamics - highlighted in Figure $\mathbf{2}$ and Table $\mathbf{2}$ - and are therefore important to account for in translational studies that involve the ocular surface:

- Basal tear turnover rate: Tear turnover rate is considered a global measure of the tear dynamics and integrity of the lacrimal functional unit. ${ }^{107,108}$ The basal tear turnover rate is reportedly $13.1-17.5 \% / \mathrm{min}$ in humans, ${ }^{109,110} 12.1 \% / \mathrm{min}$ in dogs, ${ }^{111} 6.2-7.1 \% / \mathrm{min}$ in rabbits ${ }^{112}$ and $5.2 \% / \mathrm{min}$ in mice, ${ }^{113}$ no information was available in rats. In other words, it takes approximately the same time for the tear film to replenish in dogs and humans ( 6-8 $\mathrm{min}$ ) but the duration is longer in rabbits ( 14-16 min) and mice ( $20 \mathrm{~min})$. The slow tear turnover of rabbits and rodents has important repercussions in translational 
research, including a longer precorneal retention time of instilled eyedrops (see next subsection), or exaggeration of ocular surface disease due to delayed clearance of inflammatory mediators from the tear film. ${ }^{114}$

- Tear volume: The volume of tears on the ocular surface is highest in dogs $(65.3 \mu \mathrm{L}),{ }^{111}$ followed by humans $(7-12.4 \mu \mathrm{L}),{ }^{109,115}$ rabbits $(1.9-7.5 \mu \mathrm{L})^{112,116}$ rats $(4.6 \mu \mathrm{L})^{117}$ and mice $(0.06-0.2 \mu \mathrm{L}) .{ }^{113,118}$ Canine tear volume depends on the subject's body weight but not the dog's cephalic conformation. ${ }^{111}$ Differences in study methodology notwithstanding, the canine tear volume is approximately 5 to 9 -fold larger than in humans. This discrepancy can be partly explained by the additional secretory tissue in dogs (third eyelid gland) and the larger corneal surface to lubricate in dogs (1.2-2.1 $\mathrm{cm}^{2} v s .1 .04-1.3$ $\left.\mathrm{cm}^{2}\right) .{ }^{50,71,77}$ The canine tear film may also be thicker than in humans $(15.1 \mu \mathrm{m}$ vs. $2.3-11.5 \mu \mathrm{m})$, although measurements of tear thickness were only obtained in $6 \operatorname{dogs}^{111}$ and the calculation of tear thickness is reportedly highly variable within and between species. ${ }^{119}$

- Spontaneous blink rate: The blink action distributes fresh tears on the ocular surface in a uniform layer, promotes secretion of tears from the accessory tear glands, and pumps excess tears (or instilled drop) into the nasolacrimal drainage system. Spontaneous blinking is triggered by higher centers in response to corneo-conjunctival nerve stimulation, presumably due to changes in ocular surface temperature that result from thinning and evaporation of unstable tear film. ${ }^{120}$ The spontaneous blink rate is very similar between dogs (14.2 blinks/min) ${ }^{121}$ and humans (8.5-17.6 blinks/min), ${ }^{122-124}$ although it is lower in rodents $(<5.3 \text { blinks/min })^{91,124-126}$ and much lower in rabbits $(0.05-0.19$ blinks $/ \mathrm{min}) .{ }^{2,123,127}$ In other words, humans and dogs blink approximately every 4-7 seconds, while mice/rats blink every 11 seconds (or more) and rabbits only blink every 313-1200 seconds. This large disparity in mammals' blink rate can be explained by species differences in (i) ocular surface sensitivity, (ii) tear composition, and (iii) the inherent stability of the animal's tear fluid. In fact, $(i)$ the corneo-conjunctival sensitivity is higher in humans $>$ rodents $>\operatorname{dogs}>>$ rabbits, a key parameter that is linked to spontaneous blinking as well as reflex secretion of tear components from the lacrimal glands, conjunctival goblet cells and meibomian glands; ${ }^{128}$ (ii) tear composition is unique to each species (see next section), for instance large discrepancies exist in the tear lipidomic profile of rabbits $v s$. man; ${ }^{129}$ and (iii) tear film stability is strongly associated with the maximum blink interval, as recently shown in humans. ${ }^{130}$ Tear stability is often measured with the tear film breakup time (TFBUT), defined as the interval between the last complete blink and the first appearance of a dry spot in the tear film. Results of TFBUT and other tear film diagnostics are summarized in Table 2, with care given to discard or highlight values obtained in anesthetized or sedated animals (eg., TFBUT of $29.8 \mathrm{~min}$ in sedated rabbits) ${ }^{131}$ as chemical intervention negatively impacts ocular surface homeostasis (ie., abolished blinking, reduced tear secretion).

Importantly, investigators should account for additional parameters (and their species differences) in any study that involves topical drug administration. In fact, an eyedrop can be considered as a transient ocular irritant - especially if the solution's $\mathrm{pH}$ or osmolarity is different than the tear film - thereby stimulating reflex blinking and lacrimation upon contact with the ocular surface. ${ }^{132}$

- Reflex blinking (or lack thereof): In dogs, a blink occurs immediately after eyedrop administration and is responsible for removal of any excess solution onto the periocular skin and nasolacrimal drainage system. ${ }^{40}$ The same is true in humans, in whom an instilled eyedrop is partially lost (20-30\%) due to 
reflex blinking and spillage onto the eyelids and eyelashes. ${ }^{133}$ Blinking in response to eyedrop instillation is also reported in mice ${ }^{134}$ and rats. ${ }^{135}$ In contrast, rabbits rarely blink following eyedrop administration, or do so infrequently. In one study, rabbits did not blink for 20-30 minutes after instillation of an eyedrop, and this alone could result in overestimating ocular drug exposure by 3 -fold if findings were to be extrapolated to humans. ${ }^{2}$

- Reflex tear turnover rate: Eyedrop administration abruptly increases the volume of fluid in the conjunctival sac and ocular surface. The sudden disruption in homeostasis promotes a faster nasolacrimal drainage until baseline conditions return. This physiologic response is prominent in dogs $(50 \% / \mathrm{min})^{111}$ and humans, ${ }^{109,115}$ but is minimal in rabbits $(6.1-6.9 \% / \mathrm{min}) .{ }^{112} \mathrm{In}$ fact, the tear turnover rate in rabbits is mostly unchanged whether a small $(1-5 \mu \mathrm{L})$ or large volume $(25-50 \mu \mathrm{L})$ of eyedrop is instilled on the ocular surface, ${ }^{112}$ a finding likely related to the poor corneal sensitivity and inexistent/minimal reflex blinking in this species. ${ }^{2,92}$ No available report in mice or rats can be found in the literature.

- Volumetric capacity of the palpebral fissure: The surface of the canine eye can 'hold' on average 31.3 $\mu \mathrm{L}$ of fluid, ${ }^{40}$ nearly identical to the volumetric capacity of the human eye $(25-30 \mu \mathrm{L})^{109,136}$ and the volume of a single ophthalmic drop $(35 \mu \mathrm{L}) .{ }^{137}$ Of note, the volumetric capacity of the canine eye is positively correlated with the length of the palpebral fissure, ${ }^{40}$ and may be larger in breeds larger than Beagles (eg., German Shepherd dogs). ${ }^{137}$ The exact volumetric capacity of the eye is not reported in laboratory species, but is presumably around $10-25 \mu \mathrm{L}$ in rabbits (based on drug quantification in tears at various instilled volumes), ${ }^{112,138} \leq 5 \mu \mathrm{L}$ in mice ${ }^{139,140}$ and $\leq 20 \mu \mathrm{L}$ in rats. ${ }^{141}$

\subsection{Tear film composition}

The tear film is a complex biological fluid containing thousands of compounds of diverse structures and functions, including proteins, lipids and mucins, as well as minor constituents such as electrolytes, vitamins, and growth factors. ${ }^{36,142}$ The integrated interactions of these constituents are responsible for the promotion of a stable tear film and, ultimately, the homeostasis of the ocular surface. Species differences in tear film components are summarized in Table 3.

Proteins - The total protein content is generally similar in dogs $(5.2-14.6 \mathrm{mg} / \mathrm{mL})^{143}$ and humans $(6.0-11.0$ $\mathrm{mg} / \mathrm{mL}),{ }^{144}$ although qualitative and quantitative differences exist. Specifically, the three major constituents of the human tear proteome (lactoferrin, lysozyme, lipocalin) ${ }^{144}$ are only detected at low levels in dogs, ${ }^{145-}$ ${ }^{150}$ although the relative abundance of other common proteins (eg., lacritin, secretory IgA, serum albumin) is generally similar between the two species. Importantly, homologous proteins have been described in canine tears and may play similar functions to their human counterparts - for instance, transferrin is an iron-binding protein with similarities to lactoferrin, while major canine allergen is an abundant protein in canine tears with similarities to lipocalin. ${ }^{148-150}$ From a qualitative aspect, a recent in-depth proteomic study showed that 25 out of 125 proteins detected in canine tears were common to humans. ${ }^{149}$ In rabbits, Wei et al. found that the total protein content was two-fold higher in rabbits compared with humans $(20.6 \mathrm{mg} / \mathrm{mL}$ vs. $9.4 \mathrm{mg} / \mathrm{mL}$ ), although the number of different proteins detected in tear samples was lower in rabbits. ${ }^{151}$ Other differences in tear proteins among species are summarized in Table $\mathbf{3}$. 
Mucins - Ocular mucins are large glycoproteins expressed by conjunctival goblet cells, the corneal epithelium and the lacrimal gland(s), playing important roles on the ocular surface in lubrication, wettability and barrier function. ${ }^{152}$ The main secretory mucin, MUC5AC, is described at large levels on the ocular surface of humans and animals. ${ }^{11,55,152}$ The expression of membrane-associated mucins, however, differs among species. In a recent study by Leonard et al., dogs were found to have a very similar pattern of mucin expression to that of humans and rhesus macaques, with MUC16 being the most abundant mucin transcript. ${ }^{153}$ In contrast, the rabbit had a unique mucin expression pattern with all mucin transcripts expressed at relatively similar levels; as such, the authors concluded that the predictive value of the rabbit as a model in ocular surface studies should be called into question. ${ }^{153}$ In another study, the majority of ocular mucins detected in dogs and rabbits were neutral fucosylated glycans, while the ones in humans were mainly negatively charged sialylated glycans; ${ }^{154}$ however, the experiment lysed the ocular surface epithelium and could not discriminate between mucins of differing origin.

Lipids - In a comprehensive lipidomic study comparing the meibum collected in several species, Butovich et al. found that the highest degree of biochemical similarity with humans was observed in mice, closely followed by the dog. ${ }^{129}$ An earlier study by Butovich et al. also reported the close resemblance of the tear lipid composition between dogs and humans. ${ }^{155}$ In these 3 species (humans, dogs, mice), the major lipid classes included wax esters, cholesterol esters, and o-acyl- $\omega$-hydroxy fatty acids (OAHFA). In contrast, the major lipid classes in rabbit tears were DiHL esters (24,25-dihydro--lanosterol esters), diacylated diols, and OAHFA, with low to trace amounts of wax and cholesterol esters. ${ }^{129}$ Such discrepancy between rabbits and humans was confirmed in a separate study by Wei et al, who noted significant differences in the tear film concentrations of triglycerides (higher in rabbits), free cholesterol (lower in rabbits), phosphatidylcholine (higher in rabbits) and phosphatidylethanolamine (higher in rabbits). ${ }^{151}$ Taken together, the authors of these two studies argued that the rabbit is too different to serve as a valid animal model for humans, at least from a biochemical standpoint.

\section{Tear collection for bioanalytical purposes}

The tear film, a complex body fluid uniquely exposed to both internal and external environments, contains numerous endogenous and exogenous molecules (eg., proteins, lipids, mucins, xenobiotic) that can be assayed for clinical or research purposes. Topically and systemically administered drugs can be quantified in tear fluid to determine the clinical efficacy and dosing frequency from fitting of kinetic data. ${ }^{156-}$ 160 Multiple 'omics' approaches can also be utilized for analysis of the tear fluid including proteomics, ${ }^{149,150,161-166}$ lipidomics ${ }^{129,155,167,168}$ and metabolomics, ${ }^{168}$ providing valuable information for the development of novel diagnostics and therapeutics in ophthalmology, as well as biomarkers identification for various ocular and systemic diseases. ${ }^{169-171}$ However, collecting tears and obtaining reproducible analytical results in ophthalmology is challenging; in particular, the volume of tear fluid is limited (unlike other biological fluids, such as blood or urine), and the biochemical profile of a tear sample is intimately affected by the collection, storage, extraction, handling, and analytical methods used by the investigator. In this section, we review the main sampling methods reported in the scientific literature and discuss their respective advantages and limitations. Further, based on the authors' experience with dogs in clinical and research settings (board-certified veterinary ophthalmologist [LS] and pharmacologist [JPM]), the section provides recommendations specific to canine subjects and their use in translational research (Figure 3). 


\section{1. $\quad$ Direct tear sampling}

A microcapillary glass tube $(1-10 \mu \mathrm{L})$ placed in contact with the inferior lacrimal lake is the most commonly reported technique to collect tear fluid. This method directly samples tear fluid by capillary action and is extensively described in humans, ${ }^{144,161,166,172-185}$, dogs, ${ }^{147,150,186-189}$ rabbits, ${ }^{183,184,187,190,191}$ mice, ${ }^{192,193}$ and rats. ${ }^{147,183,194,195}$ Other direct techniques (seldom reported) involve micropipettes, ${ }^{196}$ polypropylene tubing ${ }^{147}$ or polytetrafluoroethylene tubing. ${ }^{172}$ With capillary glass tubes, it is possible to obtain unaltered tear samples by avoiding reflex tearing from ocular irritation, especially if the collection is performed by an experienced operator on a cooperative patient. The minimal binding of tear compounds to glass is another reported advantage of capillary tubes. However, the main limitation of microcapillary collection is the long collection time, generally $\geq 5 \min ^{174,180,184,185,190,193}$ - this is particularly true in small laboratory animals, with up to 15-30 minutes and 15-60 min required to collect sufficient tear fluid in rabbits ${ }^{184,190}$ and rodents (mice and rats), ${ }^{193,194}$ respectively. Another critical limitation of direct sampling is the low volume of tear fluid retrieved, generally $\leq 5 \mu \mathrm{L}^{144,147,166,172,175,177-179,182,183,185,191-193}$ - as such, the small sample collected may be grossly insufficient in some individuals, ${ }^{144,188}$ may require excessive dilution that renders the target analyte undetectable, ${ }^{189}$ and does not take into account possible losses (eg., transfer, storage) or the need to repeat certain assays in duplicates.

Several strategies can be used to overcome current obstacles with the volume of the tear volume; however, each come with its own set of drawbacks (listed in parentheses): (i) Sedate or anesthetize the animal to extend collection duration and obtain a larger volume (altered lacrimal functional unit and ocular surface homeostasis); ${ }^{147,184,190,192-195}$ (ii) Pool tear samples from several subjects (reduced statistical power and loss of information regarding inter-individual variability), ${ }^{161,187,192}$ (iii) Induce reflex tearing with a stimulant either physical (eg.. irritation to nasal mucosa or cornea), chemical (eg., parenteral pilocarpine or ammonium fumes) or physiological (eg., yawn or sneeze reflex) - thereby accelerating tear flow and shortening collection time (diluted tear sample, unable to control flow rates); ${ }^{180,193,194,197}$ (iv) Instill fluid (eg., saline) on the ocular surface immediately prior to tear collection, a process called 'flush' or 'washout' that yields a larger tear sample in a shorter amount of time (diluted tear sample, non-standardized instilled volume, non-homogenous mixing of fluid with tears). ${ }^{174,180,192,193,195,197,198}$ In particular, the diluting effect of reflex tearing or flush methods may drop the concentration of low-abundant compounds below the analytical limit of quantification, and potentially mask differences between groups due to reduced variance in tear composition. ${ }^{174,199} \mathrm{~A}$ third limitation of microcapillary tubes is the technical difficulty associated with the collection method. In fact, it is nearly impossible (or very challenging) to avoid reflex lacrimation in a consistent manner, even with cooperative patients and experienced personnel $;^{175,176,180,197,200}$ for instance, capillary tear collection by Markoulli et al. resulted in tear secretion that was approximately 4fold faster than basal tear flow in humans (4.6 vs. $1.2 \mu \mathrm{L} / \mathrm{min}$, respectively). ${ }^{109,180}$ Of note, sampling itself may act as a stimulant due to environmental factors (air movement, light) ${ }^{200}$ and the stress/anxiety experienced by patients when capillary tubes are used. ${ }^{173,176,179,197}$ Importantly, the technical challenge of capillary tubes is amplified in animals given their uncooperative nature, and in any patient with aqueous tear deficiency given the low tear volume; tear sampling can be extra slow in these cases, possibly impeded/interrupted if an air bubble or mucinous material enters the capillary lumen. ${ }^{185}$

Taken together, although direct tear collection remains the preferred method of some investigators given the 'undisturbed' tear sample retrieved, ${ }^{199}$ the serious drawbacks listed above have prompted a growing number of clinicians and researchers to consider indirect tear sampling in humans as suitable alternatives. ${ }^{149,176}$ It is the authors' opinion that indirect tear sampling is also preferred in dogs, cats and 
laboratory animals. Ultimately, the patient's safety and comfort during tear collection is paramount and, as suggested by Berta, 'it is better to use well-controlled methods than to try to cause as little irritation as possible ${ }^{200}$

\section{2. $\quad$ Indirect tear sampling}

Indirect techniques involve tear fluid absorption with either Schirmer tear strips or absorbent sponges, followed by extraction of tear compounds by centrifugation and/or solvent elution.

Schirmer tear strips are routinely used to measure tear volume for clinical assessment of dry eye disease in humans and veterinary species. ${ }^{165,201-206}$ The strips are made of Whatman no. 41 cellulose filter paper and possess specific characteristics to promote tolerance (5mm width $\mathrm{x} 35 \mathrm{~mm}$ length, $0.22 \mathrm{~mm}$ thick, $20-25 \mu \mathrm{m}$ porosity, foldable extremity for ease of insertion). ${ }^{197,207}$ In addition to their conventional use for aqueous tear assessment, Schirmer strips can retrieve tear fluid for bioanalytical purposes in humans, ${ }^{144,161,165,166,173,176,208} \mathrm{dogs},{ }^{143,149,156,159,160,186,209}$ and small laboratory species. ${ }^{191,210,211}$ For instance, Schirmer strips were used for in-depth characterization of proteomics in human ${ }^{162}$ and canine tears, ${ }^{149}$ and can also successfully recover specific analytes such as cytokines, ${ }^{208,212}$ clusterin, ${ }^{144}$ and xenobiotics. ${ }^{156,158-}$ $160,191,213$

Absorbent sponges exist in different material types such as cellulose, ${ }^{179,181,214,215}$ polyvinyl acetal, ${ }^{143,159,173,181,191,214,216,217}$ polyester, ${ }^{185,188,217}$ and polyrurethane. ${ }^{181}$ A material with hydrophilic and hydrophobic properties (eg., polyvinyl acetal, polyurethane $)^{181,214}$ is generally preferred in order to optimize the amount of fluid absorbed and the amount of fluid retrieved from the sponge. For tear fluid collection, the sponge is held against the lacrimal lake by the operator (to minimize reflex tearing), ${ }^{179,185,188,191,217}$ or placed beneath the lower eyelid for a given period of time. ${ }^{159,181,214}$ Tear fluid recovered from absorbent sponges can be assayed for selected tear compounds, similar to Schirmer strips.

Indirect tear collection is superior to direct capillary sampling in many aspects, namely: (i) Improved tolerance and acceptability by patients; ${ }^{144,176,217,218}$ (ii) Ease of use and operator safety, especially for Schirmer strips, allowing non-specialists to perform the procedure with minimal training; ${ }^{176,181,217}$ and (iii) Larger volume of tears collected in a shorter duration. ${ }^{179,181,185,191}$ Absorbent materials collect tears but can also pick up cellular and extracellular 'debris', an attribute considered beneficial by some as the sample obtained is more representative of the dynamic microenvironment at the ocular surface, ${ }^{219}$ but also perceived as a limitation by others as the fluid retrieved is not 'pure' tears. ${ }^{199}$ On this note, the main limitation of indirect sampling is the 'invasiveness' of the technique, at risk of promoting reflex tearing and altering the composition of the tear fluid; indeed, several studies showed variable tear composition between directly- and indirectly- collected samples, with notable differences in the qualitative and quantitative profiles obtained for tear lipids ${ }^{167}$ and tear proteins. ${ }^{161,166,182,220}$ Another important drawback is related to the adsorptive properties of Schirmer strips or absorbent sponges, ie. incomplete release of tear compounds following extraction; ${ }^{143,159,207,208,216}$ however, the authors believe this limitation can be minimized/controlled with adequate precautions (see section 3.3).

\subsection{Proposed strategy for lachrymal determinations in dogs}

Schirmer strips vs. absorbent sponges - Sponges can rapidly absorb up to $106 \mu \mathrm{L}$ of tear fluid in $\operatorname{dogs},{ }^{214}$ while the maximum absorptive capacity of Schirmer strips is $\sim 31 \mu \mathrm{L}$ (ie., $35 \mathrm{~mm}$ wetness). ${ }^{221}$ With sponges, however, the operator can only control the duration of tear collection and not the volume of tears soaked up in each individual. The resulting variability in tear volume absorbed often translates into large intra- and 
inter-subject variability in the concentration of the compound(s) of interest, as shown for protein content ${ }^{143}$ and various drugs such as doxycycline, ${ }^{159}$ minocycline, ${ }^{222}$ voriconazole, ${ }^{223}$ and ofloxacin. ${ }^{191}$ On the other hand, the ability to control the volume of tears absorbed with Schirmer strips (ie., same mm mark) generally improves the reproducibility of the results. ${ }^{143,159,160,224}$

As such, the authors prefer $(i)$ absorbent sponges for collecting large volumes of tears in canine subjects $i e$., for further use as blank tears in bioanalytical assays for example - and (ii) Schirmer strips for collecting known amounts of tears in any scenario where reproducibility of the data is important (ie., for group comparisons, or follow-up of the same individual over time).

Schirmer strips for protein quantification - For consistency purposes, the authors recommend the use of dye-free Schirmer tear strips, being consistent with the manufacturer and lot number (given the reported variability in absorptive and adsorptive properties among Schirmer strips), ${ }^{225,226}$ as well as the time of collection (eg., morning) $)^{176}$, because of known diurnal variability in lacrimal protein composition in humans ${ }^{182,197}$ and dogs. ${ }^{224}$ The distal end of the Schirmer strips should remain in position (ventrolateral conjunctival fornix) until $20 \mathrm{~mm}, 25 \mathrm{~mm}$ or $30 \mathrm{~mm}$ wetness is reached. ${ }^{160,186,209,221,224}$ Strip wetness $<20$ $\mathrm{mm}$ is discouraged given the potential 'concentrating effect' of the absorbent filter with low tear volumes, ${ }^{143}$ while complete wetness of the strip $(35 \mathrm{~mm})$ should be avoided as the total protein content is significantly greater with $35 \mathrm{~mm}$ compared to $20-30 \mathrm{~mm}$ mark, ${ }^{221}$ likely due to vascular fragility and excessive irritation ensued by the prolonged test duration. Importantly, investigators should be consistent with the selected mm- mark (strip wetness) within and between patients in order to standardize the volume of tears collected among subjects. This strategy provides a lower coefficient of variability in tear protein content compared to ophthalmic sponges ${ }^{143}$ and capillary glass tubes ${ }^{224}$ in dogs, thereby improving the reliability and reproducibility of the data. Tear extraction and protein analysis can be done directly after tear collection, or can be postponed to a future date as long as Schirmer strips are stored immediately at $-80^{\circ} \mathrm{C}$ and the stability of the compound(s) of interest is verified. ${ }^{197}$ Following tear extraction with centrifugation, ${ }^{143,176,221,224}$ elution in solvent, ${ }^{144,149,161,162,186}$ or a combination of both, ${ }^{208,227}$ total protein content (TPC) should be quantified in order to standardize the amount of sample used for subsequent analyses. ${ }^{149,162}$ The authors' preferred method is infrared spectroscopy with Direct Detect ${ }^{\mathrm{TM}}$ (EMD Millipore, Danvers, MA) as the technique utilizes merely $2 \mu \mathrm{L}$ of tear sample, without any of the drawbacks of colorimetric protein assays (eg., Bradford, Lowry), including variability with specific protein composition and potential contamination from the absorbent material. ${ }^{179,228}$

Schirmer strips for drug quantification - The following steps should be considered to optimize drug quantification in pharmacological studies:

- Study design: In studies that assess tear film pharmacokinetics following topical drug administration, one must consider a potential limitation associated with Schirmer strips which remove most of the tear fluid in early collection times, thereby negatively impacting the 'true' tear concentration at later time points. ${ }^{197}$ For this reason, the authors recommend to conduct pharmacokinetic studies in tears over several days (eg., 10 days for 10 collection time points), repeating topical administration each day with a standardized volume and limiting the collection to a single time point per day. An alternative is to use a larger sample size and randomly allocate each time point to a subset of individuals or eyes (eg., 40 eyes with $n=5$ eyes for 8 separate time points), ${ }^{156}$ although this method should account for differences between subjects such as greater tear volumes in dogs of larger body weight. ${ }^{111}$ 
Another aspect to consider in the study design is the assessment of drug kinetics in diseased eyes, rendering the study results more clinically applicable (see section 4.2); in fact, tear film concentrations and ocular bioavailability are likely to differ in healthy $v s$. diseased eyes (eg., excessive lacrimation, increased absorption into congested conjunctival vessels, albumin binding), ${ }^{160,229}$ yet the majority of ocular studies to date are conducted in healthy individuals which is a clear limitation for translation of research findings from bench to bedside.

- Tear collection with Schirmer strips: It is important to homogenize the volume collected within and between subjects by standardizing the extent of strip wetness ( $\geq 20 \mathrm{~mm}$ mark) - this approach limits the variability in tear concentrations related to the collection method itself. ${ }^{159,160}$ The amount of wetness is then converted to a volume $(\mu \mathrm{L})$ in order to calculate actual tear film concentrations; ${ }^{221}$ data reporting is otherwise limited to $\mu \mathrm{g} / \mathrm{g}$ of strip. ${ }^{156,191} \mathrm{In}$ dogs, the median volume absorbed by Schirmer strips is $18 \mu \mathrm{L}(20 \mathrm{~mm}), 22 \mu \mathrm{L}(25 \mathrm{~mm}), 26 \mu \mathrm{L}(30 \mathrm{~mm})$ and $31 \mu \mathrm{L}(35 \mathrm{~mm})$, information obtained from hundreds of in vivo collections with pre- and post- weighing of Schirmer strips). ${ }^{221}$ This method is preferred over in vitro use of phosphate buffered saline ${ }^{208}$ given differences in fluid viscosities and the inability of an in vitro experiment to mimic the complex dynamics of tear absorption noted in vivo (eg., rapid initial uptake, ${ }^{204}$ tear evaporation).

In parallel, investigators should record the duration of tear collection (eg., 50 seconds to reach $20 \mathrm{~mm}$ ) in order to calculate a flow rate $(\mu \mathrm{L} / \mathrm{min})$ for each sample obtained. ${ }^{159,180} \mathrm{In}$ one of our experiments with doxycycline in dogs, flow rate did not influence tear concentrations, ${ }^{159}$ but this finding might not be generalizable to other drugs and/or other species of interest.

- Extraction protocol optimization: A drug can be extracted from Schirmer strips via centrifugation, solvent elution, or a combination of both methods. However, a single extraction protocol cannot be generalized to all pharmacological studies as the specific physicochemical properties of each drug (eg., molecular weight, lipophilicity) can affect the extraction efficiency from the filter papers. ${ }^{207}$ As such, investigators should consider conducting a preliminary experiment to determine the optimal extraction protocol for the drug studied, and report specific recovery rates (mean \pm standard, range). For instance, the recovery of prednisone and prednisolone was maximized with a combination of centrifugation and elution in methyl tert-butyl ether, a solvent chosen over methanol and acetonitrile based on superior drug extraction from Schirmer strips (Figure 4). ${ }^{160}$ Of note, a comprehensive review of all reported protocols is beyond the scope of the present work, and further research is warranted to assess the potential benefits (or lack thereof) of extraction steps reported in the literature, such as cutting Schirmer strips into small pieces ${ }^{162,165,213}$ or using ultrasonic agitation. ${ }^{160,165,197}$ Ultimately, an optimized extraction protocol is important as it enhances the reliability of the data at hand, improving the sensitivity of the bioassay, and providing drug concentrations closer to 'true' biological levels in the tear film.

- Bioanalytical method optimization: First, internal standard should be applied directly onto the dry portion of the Schirmer strip (Figure 4), ${ }^{160} i e$. before tear extraction instead of post-elution with solvent as routinely described; ${ }^{156,213}$ this step allows for drug quantification to account for potential variability in extraction efficiency between samples. Second, the standard calibration curve solutions should be constructed by spiking known drug concentrations and internal standard onto Schirmer strips, followed by the same extraction protocol as for biological samples; this step is equivalent to 'spike and recover' 
experiments recommended for other analytes such as cytokines ${ }^{216}$ and proteins. ${ }^{207}$ Third, actual tear fluid should be used whenever possible as the selected matrix for standard calibration curve and quality control solutions, ${ }^{159,160,223}$ as the reported surrogates (eg., artificial tear solution $)^{230}$ do not account for chemical interferences and matrix effects that typically occur with a complex biological fluid (eg., ionization suppression). ${ }^{223}$ Blank tears can be collected with absorbent materials prior to study initiation, retrieving up to $84 \mu \mathrm{L}$ in 1 min with ophthalmic sponges in $\operatorname{dogs}^{214}$ and $132 \mu \mathrm{L}$ in 12 min with successive substitutions of polyurethane mini-sponges in humans. ${ }^{181}$

\section{Spontaneous and experimental models of ocular surface disorders in dogs}

4.1. Spontaneous ocular surface diseases in dogs with translational applications to humans

Spontaneous ocular surface disorders are common in dogs and represent one of the major causes for referral visits to veterinary practitionners. ${ }^{231}$ In contrast, naturally-acquired ocular surface pathology is much less common in rabbits ${ }^{232,233}$ and is rare in mice and rats. ${ }^{234-236}$

\subsubsection{Keratoconjunctivitis sicca}

Keratoconjunctivitis sicca (KCS), or 'dry eye', represents one of the most common ocular diseases in humans with an estimated prevalence ranging from 5 to $50 \%$ in different regions worldwide. ${ }^{237}$ The disease is also very common in dogs (prevalence 1.5 to $35 \%$ ), ${ }^{231}$ although not a single report of spontaneous KCS case exists in laboratory animals such as rabbits, mice and rats.

The pathogenesis of KCS is very complex, involving diverse physio-anatomical factors such as lacrimal gland integrity, meibomian glands function, hormonal balance and neuronal input. ${ }^{237}$ Numerous models of dry eye have been established in animals over the years, ${ }^{238-240}$ helping to elucidate complex pathological mechanisms involved in KCS and develop novel therapeutics for humans. However, the major drawbacks of most animal models are the acute nature of the induced pathology ( $v s$. chronic disease in humans) and the focus on a single component of the lacrimal functional unit, such as surgically removing the lacrimal gland in mice to reduce tear secretion, ${ }^{32}$ cauterizing the lid margin in rats to induce meibomian gland dysfunction, ${ }^{241}$ or instilling topical $1 \%$ atropine in rabbits to disrupt the efferent neural input. ${ }^{242}$ These experimental models can be generally improved by increasing the number of interventions in the study animals, for instance combining lacrimal glands removal with chemical destruction of the conjunctiva in rabbits, ${ }^{243}$ or combining scopolamine administration with desiccating environmental stress in mice; yet, these complex models remain suboptimal at best given the acute nature and the inability to fully encompass the complexity of KCS pathophysiology. ${ }^{244}$ Dogs, on the other hand, develop KCS in a spontaneous manner and do not require invasive procedures to disrupt the lacrimal functional unit. ${ }^{201,205}$ Most importantly, the disease is clinically and immunopathologically similar to dry eye in humans, and possesses several attributes that are beneficial for translational research:

- Canine KCS is typically bilateral, develops in middle-aged animals, is more common in female dogs and in certain breeds (eg., American Cocker spaniel, English Bulldog), mimicking the diversity of dry eye in humans related to sex and race. ${ }^{201,237}$

- Immune-mediated dacryoadenitis is the most common etiology of KCS in dogs - similar to human patients with Sjögren's syndrome - in which progressive lymphocytic infiltration of the lacrimal gland(s) damages the secretory tissues and reduces aqueous tear production. ${ }^{201}$ 
- Meibomian gland dysfunction is recognized in many canine patients with ocular surface disorders, affecting tear film stability in a similar manner than evaporative dry eye in human patients. ${ }^{245}$

- Spontaneous symptoms of ocular irritation, conjunctival hyperemia and corneal scarring correlate directly with aqueous tear production, a parameter that is easily measured/quantified using a standard Schirmer tear test strip.

- Multiple diagnostic tools used in humans can easily be applied in dogs (but not rodents) given the large size of the canine globe, ${ }^{205,239}$ including tear osmometry, vital staining, strip meniscometry test, infrared meibography and corneo-conjunctival impression cytology.

- Dogs and humans display a similar responses to common therapeutics for dry eye disease; in fact, the two FDA approved anti-inflammatory drugs for dry eye disease in humans (cyclosporine, lifitegrast) were first developed in canine patients with spontaneous KCS. ${ }^{201,246}$

The main limitation to consider in dogs is the tendency for clinical signs to be more pronounced in that species vs. humans (eg., tenacious mucoid discharge, corneal melanosis, neovascularization), in part because canine KCS is often diagnosed at a later stage when owners fail to recognize more subtle clinical signs early on.

\subsubsection{Allergic conjunctivitis}

Allergic conjunctivitis is a common disorder in humans with an approximate prevalence of $40 \%$ in the North American population. ${ }^{247}$ The disease is characterized by an immunopathological reaction of the ocular surface to the external environment, resulting in clinical symptoms that range from mild conjunctivitis (seasonal or perennial) to the more severe, vision-threatening vernal keratoconjunctivitis and atopic keratoconjunctivitis. ${ }^{247}$ Over the past few decades, extensive research on small laboratory species (mice, rats, guinea pigs) has helped elucidate some of the complex molecular and cellular processes involved in the pathogenesis of ocular allergies. ${ }^{248,249}$ However, these experiments primarily relied on a relatively small selection of allergens (eg., ovalbumin, compound 48/80, ragweed pollen), using an experimental design that merely mimics acute forms of the disease - not chronic allergen exposure over months to years - therefore limiting the long-term clinical significance of these findings. On the other hand, dogs possess notable benefits for the comparative study of allergic conjunctivitis, especially when considering companion animals rather than laboratory Beagles: ( $i$ ) these animals share the same environment (and related allergens) as their human owners, unlike commonly used species who are housed in a laboratory setting; (ii) companion dogs are outbred, providing a genetic diversity background that better reflects the human population than inbred laboratory species; and (iii) dogs develop a spontaneous form of allergic conjunctivitis. Spontaneous allergic conjunctivitis is relatively common in dogs, often associated with other allergic disorders such as canine atopic dermatitis. ${ }^{250}$ Similar to humans, the clinical signs of allergic conjunctivitis involve conjunctival hyperemia, chemosis, pruritus and ocular discharge, the disease can be diagnosed with high sensitivity and specificity using the conjunctival provocation test, ${ }^{250}$ and similar therapeutics are used in both species including topical antihistamines, mast-cell stabilizers, NSAIDs and immunomodulators. ${ }^{247}$

\subsubsection{Microbial keratitis}

It is well recognized that a natural host is best suited for studying infection, as several species-specific factors (eg., anatomical, physiological, genetic, immune) closely influence the host-pathogen interactions 
and subsequent clinical response. ${ }^{251}$ These factors likely explain why rabbits and rodents - traditionally used to model ocular surface infections in humans - cannot fully recapitulate the disease presentation and progression that occur in human patients. ${ }^{252,253}$ As such, there is an emerging appreciation for the translational advantage of studying spontaneous (and not experimental) ocular infections in dogs:

- Herpetic keratitis: Recent work has highlighted the robustness and reproducibility of the canine model to study ocular herpesvirus infections and disease, ${ }^{253,254}$ showing striking similarities in the pathogenesis of canine herpesvirus-1 and herpes simplex virus-1, both members of the alphaherpesvirinae subfamily with a seroprevalence of $21-98 \%$ in dogs (CHV-1) and 67-90\% in humans (HSV-1). ${ }^{253}$

- Bacterial keratitis: The most common bacterial genera isolated from canine patients overlap with the ones recognized in human patients (Staphylococcus, Streptococcus, Pseudomonoas). ${ }^{255,256}$ In fact, the major culprit in canine bacterial keratitis (Staphylococcus pseudintermedius) is now considered an emerging zoonosis in humans. ${ }^{257}$

\subsubsection{Others}

Dogs can serve as models for other ocular surface diseases such as corneal endothelial dystrophy (analogous to Fuch's dystrophy in humans), ${ }^{258}$ limbal stem cell deficiency, ${ }^{259}$ ocular surface squamous neoplasia ${ }^{260}$ and neurotrophic keratopathy, ${ }^{261}$ among others.

4.2. Breakdown of the blood-tear barrier in dogs: A model for ocular pharmacology and therapeutics

\subsubsection{Histamine-induced conjunctivitis}

To date, the vast majority of preclinical ocular studies for evaluation of candidate drug efficacy and safety are conducted in healthy eyes - in part for simplicity, but at a higher risk of treatment failure rate when translating these findings to clinical studies. Indeed, healthy eyes do not account for the disruption of ocular homeostasis that occurs with inflammatory diseases, including (but not limited to) changes in tear film dynamics, tear composition and permeability of ocular tissues. To address this shortcoming, the authors have recently established a robust in vivo model of conjunctivitis in dogs, a translational large animal model that provides a unique opportunity for scientists to investigate the ocular surface in health and disease states. ${ }^{212}$ The model specifically focused on conjunctivitis as this condition is frequently encountered in humans and dogs, ${ }^{262,263}$ developing either as a primary condition (eg., bacterial, viral), or as a bystander to common ophthalmic diseases such as blepharitis, keratitis, uveitis and glaucoma. This model is particularly appealing given the low cost, non-invasiveness, self-resolving nature, ability to adjust the duration and severity of the disease, and shared features with naturally occurring diseases in human and veterinary medicine.

The main highlights of the translational 'large animal' model are as follows:

- The selected compound (histamine) is inexpensive and triggers local inflammation in a non-specific manner. 
- Disease severity is dose-dependent, allowing investigators to induce mild (1 mg/ml), moderate (10 $\mathrm{mg} / \mathrm{ml}$ ) or severe $(375 \mathrm{mg} / \mathrm{ml})$ conjunctivitis (Figure 5).

- Disease duration is dose-dependent, self-resolving within an average of $115 \mathrm{~min}(1 \mathrm{mg} / \mathrm{ml}), 190 \mathrm{~min}$ $(10 \mathrm{mg} / \mathrm{ml})$ or $390 \mathrm{~min}(375 \mathrm{mg} / \mathrm{ml})$. The duration of conjunctivitis can be lengthened by repeating topical histamine administration at set intervals. ${ }^{160}$

- Topical histamine is safe and generally well-tolerated, although selected eyes receiving the highest dose of histamine $(375 \mathrm{mg} / \mathrm{ml}$ ) can develop mild ocular irritation (lasting < $1 \mathrm{~min}$ ), blepharitis or miosis.

- Tear film composition changes in eyes with experimentally-induced conjunctivitis (eg., higher levels of serum albumin and inflammatory cytokines), mimicking clinical patients with ocular surface inflammation.

- A transient increase in tear quantity and decrease in tear quality occur, although tear film homeostasis is rapidly restored in $\leq 5 \mathrm{~min} .{ }^{264}$

Levels of serum albumin are increased in tear film of canine eyes with experimentally-induced or naturallyacquired conjunctivitis, ${ }^{212,224}$ a physiological variation caused by the breakdown of the blood-tear barrier (Figure 6). Disruption of the blood-tear barrier is also described in human patients with spontaneous ocular surface disorders (eg., dry eye, allergic conjunctivitis) ${ }^{182,265-267}$ and other animal species (rabbits, horses, guinea pigs). ${ }^{268-270}$ Increased vascular permeability and disruption of tight junctions between conjunctival epithelial cells likely play a role (Figure 6), ${ }^{271,272}$ although the exact etiopathogenesis is unknown and require further investigation. A few noteworthy limitations are listed here: $(i)$ the model is not adequate to study ocular allergy given the lack of characteristic features noted in canine patients with allergies (eg., follicular conjunctivitis); (ii) pro-inflammatory mediators other than histamine are also responsible for triggering conjunctival inflammation in clinical patients (eg., leukotrienes, cytokines); (iii) conjunctival inflammation is relatively short-lived (115-390 $\mathrm{min}$ ) and cannot mimic the physiological changes noted in patients with chronic conjunctivitis (eg., reduced goblet cell density).

\subsubsection{Clinical relevance of serum albumin leakage in tear film}

Elevated serum albumin levels in the tear film represents a biomarker for ocular insult or inflammation in humans, dogs and other species. ${ }^{182,212,265,270}$ In brief, plasma-derived albumin leaks onto the ocular surface from congested conjunctival vessels and mixes with the tear film; as such, albumin concentration in tears is generally low in healthy state but increases substantially in diseased eyes. ${ }^{182}$ For instance, a recent study showed that canine eyes with diverse ocular diseases (eg., corneal ulcer, uveitis, glaucoma) had lacrimal albumin levels that were up to 14.9 -fold greater than contralateral healthy eyes. ${ }^{212}$ Albumin is a relatively large protein that has a remarkable capacity for binding ligands. ${ }^{273}$ At the level of the eye, protein binding represents an important restriction to drug absorption as only the unbound fraction of the drug diffuses across the ocular tissue barriers. ${ }^{268}$ Combined with the rapid drainage of tears following eyedrop administration (in humans/dogs, not true in rabbits), any portion of drug that binds to albumin in tear film can be considered as 'lost' from a pharmacological standpoint. Broader implications of the blood-tear barrier breakdown on ocular drug pharmacokinetics are listed below:

- Reduced bioavailability for intraocular targets: The inability of bound therapeutic drugs to penetrate the cornea lowers the amount of drug available inside the eye to exert its pharmacological action. The physiological effects of increased albumin levels in tears was recently demonstrated with tropicamide 
(and to a lesser extent latanoprost) in dogs, ${ }^{229}$ as well as pilocarpine in rabbits. ${ }^{268}$ Of note, the impact of lacrimal albumin on the pharmacological activity of a given drug is likely modulated by various factors, the concentration of the formulation, the mechanism of action and the potency of the drug for its biological target. ${ }^{229}$

- Reduced bioavailability for ocular surface targets: Drug-albumin interactions in the tear film could also be detrimental for management of ocular surface disorders, for instance reducing the efficacy of therapeutics for bacterial keratitis as only the unbound portion of an antibiotic is microbiologically active. ${ }^{274}$ Preliminary experiments conducted by the authors showed that the presence of albumin results in higher minimal inhibitory concentrations (ie., reduced susceptibility) for various antibiotics against common bacterial isolates in dogs (in-house unpublished data).

- Tear film concentrations of systemically administered drugs: Drug in the plasma compartment can access the tear film by active secretion from the lacrimal gland, or passive diffusion through the conjunctival vessels. The latter is theoretically enhanced when the blood-tear barrier is disrupted. In humans, this physiological feature could explain why the concentration-time profiles of cetirizine were similar in serum and tears in patients with allergic conjunctivitis. ${ }^{157}$ In dogs, tear film corticosteroid levels were generally higher in conjunctivitis $v s$. control eyes following oral prednisone administration (up to $+64 \%$ ), although differences were not statistically significant. ${ }^{160}$ The degree of conjunctival permeation is likely to vary among therapeutic drugs given differences in their physico-chemical properties. ${ }^{275,276}$

These findings highlight the importance of conducting pharmacological studies in clinically relevant preclinical species that are able to recapitulate leaky conjunctival vessels and elevated albumin levels in the tear film of clinical patients with ocular diseases. For topical drug administration, the authors recommend using an experimental model of blood-tear barrier breakdown (eg., histamine-induced conjunctivitis or alkali burn models) $)^{212,277}$ so that albumin and other relevant proteins are already present on the ocular surface at the time the drug mixes with the tear film. ${ }^{229}$ For systemic drug administration, the authors suggest conducting a preliminary experiment to assess whether conjunctival inflammation affects tear film concentrations to a significant extent. If not, pharmacological assessment in healthy eyes should be sufficient. Incidentally, the physico-chemical properties of some drugs (eg., size, lipophilicity, polar surface area) ${ }^{275,276}$ may allow for high conjunctival permeation under normal conditions, thereby rendering differences between healthy $v s$. diseased eyes insignificant.

\subsection{Corneal injury in dogs: in vivo and ex vivo models}

Corneal injury is common in human and veterinary patients - whether due to trauma, surgery, or other causes - and the resulting corneal scar remains one of the leading causes of blindness in animals and people worldwide. ${ }^{278}$ Although small laboratory animal species are commonly used in corneal scarring research, ${ }^{279}$ results derived from these models have several limitations. The corneal thickness is much smaller in rabbits and rodents compared to humans (Table 1). In addition to thin corneas, mice and rats have corneas that are much smaller in diameter compared to people; consequently, it is often difficult to isolate the central cornea when performing the experimental procedure (eg., chemical burn) and the damage caused to surrounding limbal stem cells negatively impacts the wound healing process. Using the dog as an animal model is 
therefore more appropriate, not only due to closer resemblances in ocular surface anatomy and physiology with humans, but also the relatively high prevalence of naturally-acquired corneal pathology in the canine species. In that regard, Gronkiewicz et al. recently developed a novel in vivo corneal fibrosis model in canines; ${ }^{277}$ the authors induced corneal scarring with an alkali burn and investigated the ability of suberanilohydroxamic acid (SAHA) to inhibit fibrosis using this large animal model. The availability of such a model presents a clear opportunity for translational research (ie., intact innervation, tear film, blood supply), although experimentally-induced corneal wounding (at risk of secondary infection) and subsequent corneal scar in dogs represent potential ethical challenges. As an alternative, other authors have established ex vivo canine corneal cultures that can be used to model wound healing and assess anti-fibrotic compounds, ${ }^{280-282}$ or better understand the pathophysiology of herpesvirus in a virus-natural-host environment; ${ }^{283}$ in that study, the authors established an air-liquid canine corneal organ culture model to study acute herpetic keratitis, showing important similarities in the response to $\mathrm{CHV}-1$ to what has been described for HSV-1. ${ }^{283}$

\section{Conclusions}

"Considerable reservations may be felt about comparing results from rabbits with those from humans because of the differences between the physiology of tear flow and mixing and general anatomy. Nevertheless, the rabbit is the principal experimental animal in ophthalmology, so comparisons are needed". ${ }^{284}$ Sadly, this quote published over 45 years ago is still representative of today's state of ophthalmic research. Rabbits and small laboratory rodents continue to be used primarily (if not exclusively) in most areas of ophthalmic research, ${ }^{1}$ a concerning fact given the vast anatomical and physiological differences that exist with humans. Of note, such differences should not be regarded as merely 'weaknesses' for translational research, but rather evolutionary adaptations optimally suited to the environment and behavior of each species; for instance, rabbits likely developed a very stable tear film to limit intermittent blindness that occurs with each blink, ${ }^{285}$ thereby reducing the risk of predation. Noteworthily, recent innovations have helped mitigate some of the drawbacks of traditional laboratory species - for instance providing manual blinking and supplementary tear flow in anesthetized rabbits, ${ }^{286}$ or reverse engineering the ocular surface using human cells in vitro ${ }^{287}$ - however the authors believe the complexity of the ocular surface and integrated lacrimal functional unit cannot be fully recreated without in vivo conditions in awake subjects.

The comparative work presented throughout this review provides evidence that dogs are best suited for translational research in ophthalmology. Unlike small laboratory animals, dogs share similar anatomical and physiological features to humans, similar environmental stressors and genetic variation, and a range of naturally occurring ophthalmic diseases that closely resemble clinical phenotypes in human patients. The resemblance between dogs and humans is particularly relevant in the field of ocular pharmacology, with notable similarities in blink rate, tear turnover rate (basal, reflex), volumetric capacity of the palpebral fissure, and other factors pertinent to drug diffusion (eg., globe volume, corneal thickness); nonetheless, a few differences should be accounted for in comparative studies, such as the presence of a nictitating membrane, greater tear volume, larger corneal size and lower corneal elastic modulus in dogs. Similar to other fields of medicine, preclinical studies in ophthalmology could involve canine patients with spontaneous ocular diseases - many of which share striking resemblances with their human counterparts - 
integrating the expertise of veterinarians, physicians and basic science researchers under the umbrella of the One Health Initiative. ${ }^{6,288}$ Alternatively, or complementarily, preclinical animal work could be performed in laboratory dogs in whom ocular disease is experimentally-induced, making sure to account for the blood-tear barrier breakdown (noted in clinical patients with 'red eyes'). In all cases, tear fluid can be easily collected from canine eyes for various bioanalytical purposes, favoring Schirmer tear strips over other collection methods given the excellent safety profile and enhanced reliability in analyte quantification (eg., proteins, drugs) provided by this method. 


\section{TABLES}

Table 1. Comparative anatomy of the ocular surface and globe between humans, dogs and common laboratory species used in preclinical ophthalmic research.

\begin{tabular}{|c|c|c|c|c|c|c|}
\hline & \\
\hline & & Human & Dog & Rabbit & Mouse & Rat \\
\hline \multirow{4}{*}{$\begin{array}{c}\text { Lacrimal } \\
\text { glands and } \\
\text { nasolacrimal } \\
\text { apparatus }\end{array}$} & Lacrimal glands & $\begin{array}{c}\text { Lacrimal gland } \\
\text { Accessory glands } \\
\text { of Wolfring and } \\
\text { Krause } \\
20\end{array}$ & $\begin{array}{c}\text { Lacrimal gland, } \\
\text { Third eyelid } \\
\text { gland } \\
11,14\end{array}$ & $\begin{array}{l}\text { Lacrimal gland, } \\
\text { Third eyelid gland, } \\
\text { Infraorbital } \\
\text { (intraorbital), } \\
\text { Accessory glands of } \\
\text { Wolfring } \\
10,11,22,23\end{array}$ & $\begin{array}{c}\text { Infraorbital } \\
\text { (extraorbital) } \\
10,11,22\end{array}$ & $\begin{array}{c}\text { Infraorbital } \\
\text { (extraorbital) } \\
10,11,22\end{array}$ \\
\hline & $\begin{array}{l}\text { Lacrimal glands } \\
\text { volume }\left(\mathrm{cm}^{3}\right)^{\dagger}\end{array}$ & $\begin{array}{c}0.59-0.61 \\
18\end{array}$ & $\begin{array}{c}0.14 / 0.1 \\
17\end{array}$ & $\begin{array}{c}-/ 1.5 \\
289\end{array}$ & - & - \\
\hline & Harderian gland & $\begin{array}{c}\text { Absent } \\
22\end{array}$ & $\begin{array}{c}\text { Absent } \\
11,16\end{array}$ & $\begin{array}{c}\text { Present } \\
11,22\end{array}$ & $\begin{array}{c}\text { Present } \\
11,22\end{array}$ & $\begin{array}{c}\text { Present } \\
11,22\end{array}$ \\
\hline & $\begin{array}{c}\text { Nasolacrimal } \\
\text { drainage apparatus }\end{array}$ & $\begin{array}{c}\text { Two } \\
\text { puncta/canaliculi, } \\
\text { no flexure } \\
25,27\end{array}$ & $\begin{array}{c}\text { Two } \\
\text { puncta/canaliculi, } \\
1 \text { dorsal flexure } \\
16,25,27\end{array}$ & $\begin{array}{c}\text { Single } \\
\text { punctum/canaliculus, } \\
\text { two pronounced } \\
\text { flexures } \\
27,38,41\end{array}$ & $\begin{array}{c}\text { Two } \\
\text { puncta/canaliculi } \\
25\end{array}$ & $\begin{array}{c}\text { Two } \\
\text { puncta/canaliculi } \\
25\end{array}$ \\
\hline \multirow{4}{*}{ Eyelids } & Third eyelid & $\begin{array}{c}\text { Absent } \\
66\end{array}$ & $\begin{array}{c}\text { Present } \\
16,66\end{array}$ & $\begin{array}{c}\text { Present } \\
66\end{array}$ & $\begin{array}{c}\text { Present } \\
66\end{array}$ & $\begin{array}{c}\text { Present } \\
66\end{array}$ \\
\hline & $\begin{array}{l}\text { Palpebral fissure } \\
\text { width }(\mathrm{mm})\end{array}$ & $\begin{array}{l}21.3-34.5 \\
290\end{array}$ & $\begin{array}{c}18.9-34.1 \\
40,291\end{array}$ & $\begin{array}{l}10-16 \\
38,41,42\end{array}$ & $\begin{array}{c}3.7-5 \\
43\end{array}$ & $\begin{array}{c}6-9 \\
45\end{array}$ \\
\hline & $\begin{array}{c}\text { Interpalpebral } \\
\text { fissure area }\left(\mathrm{cm}^{2}\right)\end{array}$ & $1.8^{39}$ & $\begin{array}{c}2.2^{\S} \\
290\end{array}$ & $\begin{array}{c}1.4 \\
39\end{array}$ & $\begin{array}{c}0.13^{\ddagger} \\
43\end{array}$ & $\begin{array}{c}0.5^{\mathbb{I}} \\
45^{2}\end{array}$ \\
\hline & $\begin{array}{l}\text { Meibomian glands } \\
\text { (/eyelid) }\end{array}$ & $\begin{array}{c}20-40 \\
39,292\end{array}$ & $\begin{array}{c}20-40 \\
16\end{array}$ & $\begin{array}{l}30-50 \\
38,39,41\end{array}$ & $\begin{array}{l}20 \\
293\end{array}$ & $\begin{array}{c}20-30^{\#} \\
241\end{array}$ \\
\hline \multirow{5}{*}{ Conjunctiva } & $\begin{array}{l}\text { Conjunctival fornix } \\
\text { depth }(\mathrm{mm})^{\dagger \dagger}\end{array}$ & $\begin{array}{l}15 \\
49 \\
\end{array}$ & - & $\begin{array}{c}20.36 \\
48\end{array}$ & - & - \\
\hline & $\begin{array}{l}\text { Conjunctival } \\
\text { surface }\left(\mathrm{cm}^{2}\right)\end{array}$ & $\begin{array}{c}17.65 \\
50\end{array}$ & - & $\begin{array}{c}13.3-18.48 \# \\
50\end{array}$ & - & - \\
\hline & $\begin{array}{l}\text { Conjunctiva/Cornea } \\
\text { surface ratio }\end{array}$ & $\begin{array}{c}17.17 \\
50\end{array}$ & - & $\begin{array}{c}8.62-8.94 \\
50\end{array}$ & - & - \\
\hline & $\begin{array}{c}\text { Goblet cell spatial } \\
\text { configuration }\end{array}$ & $\begin{array}{c}\text { Individual } \\
51 \\
\end{array}$ & $\begin{array}{c}\text { Individual } \\
52\end{array}$ & $\begin{array}{c}\text { Individual } \\
51\end{array}$ & $\begin{array}{c}\text { Clusters } \\
51\end{array}$ & $\begin{array}{c}\text { Clusters } \\
51\end{array}$ \\
\hline & $\begin{array}{l}\text { Goblet cell } \\
\text { distribution }\end{array}$ & $\begin{array}{l}\text { Highest in plica } \\
\text { semilunaris and } \\
\text { lower nasal } \\
\text { fornix } \\
\text { Low in bulbar } \\
\text { conjunctiva } \\
30,53,54,56\end{array}$ & $\begin{array}{l}\text { Highest in third } \\
\text { eyelid and lower } \\
\text { nasal fornix } \\
\text { Low in bulbar } \\
\text { conjunctiva } \\
52,55\end{array}$ & $\begin{array}{l}\text { Highest in palpebral } \\
\text { conjunctiva } \\
\text { Relatively dense in } \\
\text { bulbar conjunctiva } \\
\quad 57-59\end{array}$ & - & $\begin{array}{l}\text { Highest in fornix } \\
\text { Low in bulbar } \\
\text { conjunctiva } \\
\text { Kim } 2019\end{array}$ \\
\hline
\end{tabular}




\begin{tabular}{|c|c|c|c|c|c|c|}
\hline & $\begin{array}{l}\text { Conjunctiva- } \\
\text { associated } \\
\text { lymphoid tissue }\end{array}$ & $\begin{array}{c}\text { Present } \\
61\end{array}$ & $\begin{array}{c}\text { Present } \\
16,61\end{array}$ & $\begin{array}{c}\text { Present } \\
61\end{array}$ & $\begin{array}{l}\text { Only present in } \\
\text { nictitating } \\
\text { membrane } \\
61,62\end{array}$ & $\begin{array}{c}\text { Absent } \\
61\end{array}$ \\
\hline \multirow{9}{*}{$\begin{array}{l}\text { Cornea } \\
\text { and } \\
\text { Sclera }\end{array}$} & $\begin{array}{l}\text { Corneal diameter, } \\
\text { horizontal/vertical } \\
(\mathrm{mm})\end{array}$ & $\begin{array}{c}11.8 / 11.2 \\
75,77\end{array}$ & $\begin{array}{c}13-17 / 12-16 \\
71,77\end{array}$ & $\begin{array}{c}13.4-15 / 13-14 \\
41,76,77\end{array}$ & $\begin{array}{c}2.3-2.6 /- \\
74\end{array}$ & $\begin{array}{c}2.0-6.8 / 2.0-6.7 \\
44,72,73\end{array}$ \\
\hline & $\begin{array}{c}\text { Corneal surface } \\
\left(\mathrm{cm}^{2}\right)\end{array}$ & $\begin{array}{c}1.04-1.3 \\
50\end{array}$ & $\begin{array}{c}1.2-2.1 \\
71,77\end{array}$ & $\begin{array}{c}1.55-2.03 \\
50\end{array}$ & $\begin{array}{c}0.04-0.05^{\mathrm{h}} \\
74\end{array}$ & $\begin{array}{c}0.27-0.36^{\S \S} \\
72,73\end{array}$ \\
\hline & $\begin{array}{l}\text { Corneal thickness } \\
(\mu \mathrm{m})\end{array}$ & $\begin{array}{c}505-563 \\
79\end{array}$ & $\begin{array}{c}497-594 \\
68,78\end{array}$ & $\begin{array}{l}354-407 \\
41,76,79,80\end{array}$ & $\begin{array}{c}90-137 \\
11,74,80\end{array}$ & $\begin{array}{c}159-170 \\
68,80\end{array}$ \\
\hline & $\begin{array}{c}\text { Corneal epithelial } \\
\text { thickness }(\mu \mathrm{m})\end{array}$ & $\begin{array}{c}44-55 \\
79\end{array}$ & $\begin{array}{c}52-64 \\
71,78\end{array}$ & $\begin{array}{c}45-49 \\
79\end{array}$ & $\begin{array}{c}37-46 \\
74\end{array}$ & $\begin{array}{c}26-33 \\
85\end{array}$ \\
\hline & $\begin{array}{c}\text { Endothelial cell } \\
\text { density }\left(\text { cells } / \mathrm{mm}^{2}\right)\end{array}$ & $\begin{array}{c}2732 \\
90\end{array}$ & $\begin{array}{c}2818 \\
68\end{array}$ & $\begin{array}{c}3233 \\
68\end{array}$ & $\begin{array}{c}2875 \\
68\end{array}$ & $\begin{array}{c}2242 \\
68\end{array}$ \\
\hline & $\begin{array}{c}\text { Subbasal nerve } \\
\text { plexus pattern }\end{array}$ & $\begin{array}{l}\text { Whorl-like } \\
67\end{array}$ & $\begin{array}{c}\text { Whorl-like } \\
67\end{array}$ & $\begin{array}{c}\text { Horizontal } \\
67\end{array}$ & $\begin{array}{c}\text { Whorl-like } \\
67\end{array}$ & $\begin{array}{c}\text { Whorl-like } \\
67\end{array}$ \\
\hline & $\begin{array}{l}\text { Corneal sensitivity } \\
\left(\mathrm{g} / \mathrm{mm}^{2}\right)\end{array}$ & $\begin{array}{c}0.2-1.0 \\
2\end{array}$ & $\begin{array}{c}2.16-2.9 \\
92,95\end{array}$ & $\begin{array}{c}6.21-10 \\
2,92\end{array}$ & $\begin{array}{c}0.59 \\
93\end{array}$ & $\begin{array}{c}0.42-0.47 \\
91,94\end{array}$ \\
\hline & $\begin{array}{l}\text { Stiffness/elastic } \\
\text { modulus }(\mathrm{kPa}) \text { qIII }\end{array}$ & $\begin{array}{c}16.2-33.1 \\
87,294\end{array}$ & $\begin{array}{c}1.3 \\
87\end{array}$ & $\begin{array}{c}1.1 \\
86\end{array}$ & $\begin{array}{c}25-40 \\
89\end{array}$ & $\begin{array}{c}6.2 \\
88\end{array}$ \\
\hline & $\begin{array}{l}\text { Scleral thickness at } \\
\text { the limbus (mm) }\end{array}$ & $\begin{array}{c}0.50 \\
102\end{array}$ & $\begin{array}{c}0.80 \\
101\end{array}$ & $\begin{array}{c}0.29 \\
103\end{array}$ & $\begin{array}{c}0.05-0.06 \\
105\end{array}$ & $\begin{array}{c}<0.1 \\
104\end{array}$ \\
\hline \multirow{3}{*}{ Globe } & Globe volume (mL) & $\begin{array}{c}5.7-6.0 \\
295\end{array}$ & $\begin{array}{c}5.0-5.8 \\
296\end{array}$ & $\begin{array}{l}2.3-2.9 \\
296\end{array}$ & $\begin{array}{l}0.014^{\mathrm{j}} \\
297\end{array}$ & $\begin{array}{c}0.13^{\# \#} \\
72\end{array}$ \\
\hline & $\begin{array}{l}\text { Anterior chamber } \\
(\mathrm{mL})\end{array}$ & $\begin{array}{c}0.17-0.31 \\
66,77\end{array}$ & $\begin{array}{c}0.77 \\
101\end{array}$ & $\begin{array}{c}0.28-0.30 \\
41,66,77\end{array}$ & $\begin{array}{c}0.0044-0.007 \\
11,66,77\end{array}$ & $\begin{array}{c}0.0136-0.015 \\
11,66,77\end{array}$ \\
\hline & $\begin{array}{l}\text { Vitreous chamber } \\
\qquad(\mathrm{mL})\end{array}$ & $\begin{array}{c}3.5-5.4 \\
65\end{array}$ & $\begin{array}{c}1.7-3.0 \\
101,296\end{array}$ & $\begin{array}{c}1.1-1.8 \\
66,296\end{array}$ & $\begin{array}{c}0.0053 \\
11,65\end{array}$ & $\begin{array}{c}0.013-0.054 \\
11,65\end{array}$ \\
\hline
\end{tabular}

- Information not available or not found

$\dagger$ Lacrimal gland (human), Lacrimal gland / TEL gland (dog), Lacrimal gland / Harderian gland (rabbit)

$\$$ Estimated based on clinical images ${ }^{43}$

$\S$ Estimated based on clinical images ${ }^{40}$

II Calculated based on average palpebral fissure length ${ }^{45}$

\# Estimated based on clinical images ${ }^{241}$

$\dagger \uparrow$ Central upper conjunctival sac (from fornix to lid margin)

t+ Does not account for the nictitating membrane, surgically removed prior to the experiment

$\S \S$ Estimated from corneal radius, assuming a circular shape for the cornea in rodents ${ }^{72}$

IIII Whole cornea in rats, epithelium and anterior stroma in other species

\#\# Estimated from axial length, assuming a spherical shape for the globe 
Table 2. Comparative physiology and characteristics of the ocular surface and tear film between humans, dogs and common laboratory species used in preclinical ophthalmic research.

\begin{tabular}{|c|c|c|c|c|c|c|}
\hline & & Human & Dog & Rabbit & Mouse & Rat \\
\hline \multirow{3}{*}{$\begin{array}{c}\text { Ocular } \\
\text { surface } \\
\text { physiology }\end{array}$} & $\begin{array}{c}\text { Blink rate } \\
\text { (blinks/min) }\end{array}$ & $\begin{array}{c}8.5-17.6 \\
122-124\end{array}$ & $\begin{array}{c}14.2 \\
121\end{array}$ & $\begin{array}{c}0.05-0.19 \\
2,123,127\end{array}$ & $\begin{array}{c}0-4 \\
125,126\end{array}$ & $\begin{array}{l}2-5.3 \\
91,124\end{array}$ \\
\hline & $\begin{array}{c}\text { Volumetric } \\
\text { capacity of the } \\
\text { palpebral fissure } \\
(\mu \mathrm{L})\end{array}$ & $\begin{array}{r}25-30 \\
109,136\end{array}$ & $\begin{array}{c}31.3 \\
40\end{array}$ & $\begin{array}{c}10-25 \dagger \\
112,138\end{array}$ & $\begin{array}{c}\leq 5 \\
139,140\end{array}$ & $\begin{array}{c}\leq 20 \\
141\end{array}$ \\
\hline & $\begin{array}{c}\text { Ocular surface } \\
\text { temperature }\left({ }^{\circ} \mathrm{C}\right)\end{array}$ & $\begin{array}{l}32.8-37.1 \\
298,299\end{array}$ & $\begin{array}{c}35.2 \\
300\end{array}$ & $\begin{array}{c}39.1 \\
298\end{array}$ & $\begin{array}{c}37.2 \\
298\end{array}$ & $\begin{array}{c}36.5 \\
298\end{array}$ \\
\hline \multirow{6}{*}{$\begin{array}{c}\text { Tear film } \\
\text { characteristics }\end{array}$} & $\begin{array}{c}\text { Tear film } \\
\text { thickness }(\mu \mathrm{m})\end{array}$ & $\begin{array}{c}2.3-11.5 \\
119\end{array}$ & $\begin{array}{c}15.1 \\
111\end{array}$ & $\begin{array}{c}6.5-18.4 \\
119\end{array}$ & $\begin{array}{c}7.4-21.1 \\
119,301\end{array}$ & $\begin{array}{c}2-12.6 \\
119,302\end{array}$ \\
\hline & $\begin{array}{c}\text { Lipid layer } \\
\text { thickness }(\mathrm{nm})\end{array}$ & $\begin{array}{l}62-78 \\
123,303\end{array}$ & $\begin{array}{c}13-581 \\
121\end{array}$ & $>\underset{123}{180}$ & - & $\begin{array}{l}12 \\
301\end{array}$ \\
\hline & $\begin{array}{l}\text { Tear volume } \\
(\mu \mathrm{L})\end{array}$ & $\begin{array}{c}7-12.4 \\
109,115\end{array}$ & $\begin{array}{c}65.3 \\
111\end{array}$ & $\begin{array}{c}1.9-7.5 \\
112,116\end{array}$ & $\begin{array}{c}0.06-0.2 \\
113,118\end{array}$ & $\begin{array}{l}4.6 \\
117\end{array}$ \\
\hline & $\begin{array}{c}\text { Basal tear } \\
\text { turnover rate } \\
(\% / \mathrm{min})\end{array}$ & $\begin{array}{c}13.1-17.5 \\
109,110\end{array}$ & $\begin{array}{c}12.1 \\
111\end{array}$ & $\begin{array}{c}6.2-7.1 \\
112\end{array}$ & $\begin{array}{l}5.2 \\
113\end{array}$ & - \\
\hline & $\begin{array}{l}\text { Reflex tear } \\
\text { turnover rate } \\
(\% / \mathrm{min})\end{array}$ & $\begin{array}{c}31.5-100 \\
109,115\end{array}$ & $\begin{array}{l}50 \\
111\end{array}$ & $\begin{array}{c}6.1-6.9^{\S} \\
112\end{array}$ & - & - \\
\hline & $\begin{array}{c}\text { Evaporative rate } \\
\qquad(\mu \mathrm{m} / \mathrm{min})\end{array}$ & $\begin{array}{c}3.22 \\
304\end{array}$ & - & $\begin{array}{c}0.47 \\
127\end{array}$ & - & - \\
\hline \multirow{5}{*}{$\begin{array}{c}\text { Tear film } \\
\text { diagnostics }\end{array}$} & $\begin{array}{l}\text { Schirmer tear } \\
\text { test-1 }(\mathrm{mm})\end{array}$ & $\begin{array}{c}10.0-18.6 \\
305,306\end{array}$ & $\begin{array}{c}18.1-24.3 \\
13,52,95,205,307,308\end{array}$ & $\begin{array}{l}4.6-7.6 \\
42,116,309\end{array}$ & - & $\begin{array}{c}5.6-9.4 \\
91,241\end{array}$ \\
\hline & $\begin{array}{l}\text { Phenol red } \\
\text { thread test } \\
(\mathrm{mm} / 15 \mathrm{~s})\end{array}$ & $\begin{array}{c}9-20 \\
310\end{array}$ & $\begin{array}{c}17.5-39.2 \\
95,205,307,308\end{array}$ & $\begin{array}{c}20.9-25.0 \\
42,309\end{array}$ & $\begin{array}{l}2.8-11.2 \\
125,244,311\end{array}$ & $\begin{array}{l}7.6 \\
312\end{array}$ \\
\hline & $\begin{array}{c}\text { Tear film } \\
\text { breakup time } \\
(\mathrm{sec})\end{array}$ & $\begin{array}{c}7.4-13.0 \\
305,306\end{array}$ & $\begin{array}{l}13.9-24.0 \\
13,52,205,307\end{array}$ & $\begin{array}{c}2-1788 \dagger \\
313\end{array}$ & $\begin{array}{c}5-25 \\
125,129\end{array}$ & $\begin{array}{c}5.2-6.0 \\
241\end{array}$ \\
\hline & $\begin{array}{c}\text { Tear osmolarity } \\
+(\mathrm{mOsm} / \mathrm{L})\end{array}$ & $\begin{array}{l}300.8 \\
202\end{array}$ & $\begin{array}{c}337.4-339.0 \\
205,314\end{array}$ & $\begin{array}{c}291.3 \\
315\end{array}$ & $\begin{array}{c}346.3-366.8 \\
310\end{array}$ & $\begin{array}{c}284.8 \\
312\end{array}$ \\
\hline & Tear $\mathrm{pH}$ & $\begin{array}{c}7.83 \\
316\end{array}$ & $\begin{array}{c}8.05 \\
215\end{array}$ & $\begin{array}{l}8.2 \\
316\end{array}$ & $\begin{array}{c}7.59 \\
317\end{array}$ & - \\
\hline
\end{tabular}

- Information not available or not found 
$\dagger$ Based on greater percent of drug lost at $1 \mathrm{~min}$ in rabbit eyes receiving 25 or $50 \mu \mathrm{L}$ eyedrop $v s .5$ or $10 \mu \mathrm{L}$ eyedrop, ${ }^{138}$ despite no changes in tear turnover rate for instilled volumes up to $50 \mu \mathrm{L}^{112}$

$\$$ Excludes an outlier measurement of $41-46 \mu \mathrm{m}^{318}$

$\S$ Estimated from rabbit eyes receiving a large volume instilled eyedrop $(25-50 \mu \mathrm{L})$

II Reported values prioritized studies that did not use sedation or general anesthesia

\# Values reported in $\mathrm{mm} / 5 \mathrm{~min}$ (humans) or $\mathrm{mm} / \mathrm{min}$ (all other species)

$\dagger$ Large variability in studies' methodology, most using topical and/or general anesthesia prior to testing, resulting in non-physiologic and highly variable measurements for tear film break up time tt Measurements obtained with the same device (TearLab ${ }^{\mathrm{TM}}$, OcuSense Inc., San Diego, CA). 
Table 3. Comparative composition of the major components in tear film between humans, dogs and common laboratory species used in preclinical ophthalmic research.

\begin{tabular}{|c|c|c|c|c|c|c|}
\hline & & Human & Dog & Rabbit & Mouse & Rat \\
\hline \multirow{8}{*}{ Proteins } & Lactoferrin $^{\dagger}$ & $\begin{array}{c}\text { Abundant } \\
144,147\end{array}$ & $\begin{array}{l}\text { Low } \\
146,147\end{array}$ & $\begin{array}{l}\text { Low } \\
319,320\end{array}$ & $\begin{array}{c}\text { Low } \\
147\end{array}$ & $\begin{array}{c}\text { Low } \\
147\end{array}$ \\
\hline & Lysozyme & $\begin{array}{c}\text { Abundant } \\
144,147\end{array}$ & $\begin{array}{c}\text { Low } \\
145,146\end{array}$ & $\begin{array}{c}\text { Low } \\
190,319\end{array}$ & $\begin{array}{c}\text { Low } \\
147\end{array}$ & $\begin{array}{c}\text { Low } \\
147\end{array}$ \\
\hline & Lipocalin ${ }^{*}$ & $\begin{array}{c}\text { Abundant } \\
144,147,148\end{array}$ & $\begin{array}{c}\text { Low } \\
\text { to moderate } \\
146,147,149,150\end{array}$ & $\begin{array}{c}\text { Low } \\
147,148,319,321\end{array}$ & $\begin{array}{l}\text { Low } \\
147,198\end{array}$ & $\begin{array}{c}\text { Absent } \\
147,148\end{array}$ \\
\hline & Lacritin & $\begin{array}{c}\text { Moderate } \\
144\end{array}$ & $\begin{array}{l}\text { Moderate } \\
\quad 322\end{array}$ & - & $\begin{array}{c}\text { Absent } \\
198\end{array}$ & $\begin{array}{c}\text { Present } \\
323\end{array}$ \\
\hline & Secretory IgA & $\begin{array}{c}\text { Moderate } \\
144\end{array}$ & $\begin{array}{c}\text { Moderate } \\
146,324,325\end{array}$ & $\begin{array}{c}\text { Present } \\
22\end{array}$ & $\begin{array}{c}\text { Low } \\
11\end{array}$ & $\underset{326}{\text { Moderate }}$ \\
\hline & $\begin{array}{l}\text { Serum } \\
\text { albumin }\end{array}$ & $\begin{array}{c}\text { Low } \\
182\end{array}$ & $\begin{array}{c}\text { Low } \\
146,150,212\end{array}$ & $\begin{array}{c}\text { Low } \\
190,319\end{array}$ & $\begin{array}{c}\text { Present } \\
198\end{array}$ & - \\
\hline & Peroxidase & $\begin{array}{c}\text { Low } \\
327\end{array}$ & $\begin{array}{l}\text { Low } \\
146,325\end{array}$ & $\begin{array}{c}\text { Absent } \\
190\end{array}$ & - & $\begin{array}{c}\text { Abundant } \\
194\end{array}$ \\
\hline & Amylase & $\begin{array}{c}\text { Low } \\
327\end{array}$ & - & $\begin{array}{c}\text { Absent } \\
190\end{array}$ & - & $\begin{array}{c}\text { Low } \\
194\end{array}$ \\
\hline \multirow{3}{*}{ Mucins } & MUC5AC & $\begin{array}{c}\text { Present } \\
11\end{array}$ & $\begin{array}{c}\text { Present } \\
11,55\end{array}$ & $\begin{array}{c}\text { Present } \\
11\end{array}$ & $\begin{array}{c}\text { Present } \\
11\end{array}$ & $\begin{array}{c}\text { Present } \\
11\end{array}$ \\
\hline & $\begin{array}{l}\text { MUC1, } \\
\text { MUC4, } \\
\text { MUC16 }\end{array}$ & $\begin{array}{c}\text { MUC16 >> } \\
\text { MUC1 > } \\
\text { MUC4 } \\
153\end{array}$ & $\begin{array}{c}\text { MUC16 >> } \\
\text { MUC1 > MUC4 } \\
153\end{array}$ & $\begin{array}{c}\mathrm{MUC1} \approx \\
\mathrm{MUC4} \approx \\
\mathrm{MUC16} \\
153\end{array}$ & $\begin{array}{c}\text { Present } \\
328\end{array}$ & $\begin{array}{c}\text { Present } \\
329\end{array}$ \\
\hline & $\begin{array}{l}\text { Major O- } \\
\text { glycans }\end{array}$ & $\begin{array}{c}\text { Sialylated } \\
\text { glycans } \\
154\end{array}$ & $\begin{array}{c}\text { Fucosylated } \\
\text { glycans } \\
154\end{array}$ & $\begin{array}{c}\text { Fucosylated } \\
\text { glycans } \\
154\end{array}$ & - & - \\
\hline \multirow{8}{*}{ Lipids } & Wax esters & $\begin{array}{c}\text { Abundant } \\
129,155\end{array}$ & $\begin{array}{c}\text { Abundant } \\
129,155\end{array}$ & $\begin{array}{c}\text { Low } \\
129\end{array}$ & $\begin{array}{c}\text { Abundant } \\
129\end{array}$ & $\begin{array}{c}\text { Present } \\
330\end{array}$ \\
\hline & Cholesterol & $\begin{array}{l}\text { Low } \\
129,155\end{array}$ & $\begin{array}{l}\text { Low } \\
129,155\end{array}$ & $\begin{array}{c}\text { Low } \\
129\end{array}$ & $\begin{array}{c}\text { Low } \\
129\end{array}$ & $\begin{array}{c}\text { Abundant } \\
330\end{array}$ \\
\hline & $\begin{array}{c}\text { Cholesteryl } \\
\text { esters }\end{array}$ & $\begin{array}{c}\text { Abundant } \\
129,155\end{array}$ & $\begin{array}{c}\text { Abundant } \\
129,155\end{array}$ & $\begin{array}{c}\text { Low } \\
129\end{array}$ & $\begin{array}{c}\text { Abundant } \\
129\end{array}$ & - \\
\hline & DiHL & $\begin{array}{c}\text { Low } \\
129,155\end{array}$ & $\begin{array}{c}\text { Low } \\
129,155\end{array}$ & $\begin{array}{c}\text { Low } \\
129\end{array}$ & $\begin{array}{c}\text { Low } \\
129\end{array}$ & - \\
\hline & DiHL esters & $\begin{array}{l}\text { Low } \\
129,155\end{array}$ & $\begin{array}{l}\text { Low } \\
129,155\end{array}$ & $\begin{array}{c}\text { Abundant } \\
129\end{array}$ & $\begin{array}{c}\text { Low } \\
129\end{array}$ & - \\
\hline & DiAD & $\begin{array}{c}\text { Low } \\
129,155\end{array}$ & $\begin{array}{l}\text { Low } \\
129,155\end{array}$ & $\begin{array}{c}\text { Abundant } \\
129\end{array}$ & $\begin{array}{c}\text { Low } \\
129\end{array}$ & - \\
\hline & OAHFA & $\begin{array}{c}\text { Abundant } \\
129,155\end{array}$ & $\begin{array}{c}\text { Abundant } \\
129,155\end{array}$ & $\begin{array}{c}\text { Abundant } \\
129\end{array}$ & $\begin{array}{c}\text { Abundant } \\
129\end{array}$ & - \\
\hline & Chl-OAHFA & $\begin{array}{c}\text { Moderate } \\
129,155\end{array}$ & $\begin{array}{c}\text { Moderate } \\
129,155\end{array}$ & $\begin{array}{c}\text { Low } \\
129\end{array}$ & $\begin{array}{c}\text { Moderate } \\
129\end{array}$ & - \\
\hline
\end{tabular}




\begin{tabular}{|c|c|c|c|c|c|c|}
\hline & \multirow{2}{*}{ Others $\S$} & Low & Low & Low & Low & 129 \\
& 129,155 & 129,155 & 129 & - \\
\hline
\end{tabular}

- Information not available or not found

$\dagger$ Homologous iron-binding protein called transferrin is reported in dogs ${ }^{146}$ and rabbits ${ }^{319}$

$\$$ Homologous proteins are reported in dogs (major canine allergen), ${ }^{148-150}$ rabbits (lipophilin) ${ }^{151}$ and rats $(\text { VEGr1) })^{148}$

$\S$ Triacylglycerol, squalene, ceramides, phospholipids and sphingomyelins. 


\section{FIGURES AND FIGURE LEGENDS}

Figure 1. Graphical representation of the canine ocular surface and lacrimal functional unit.

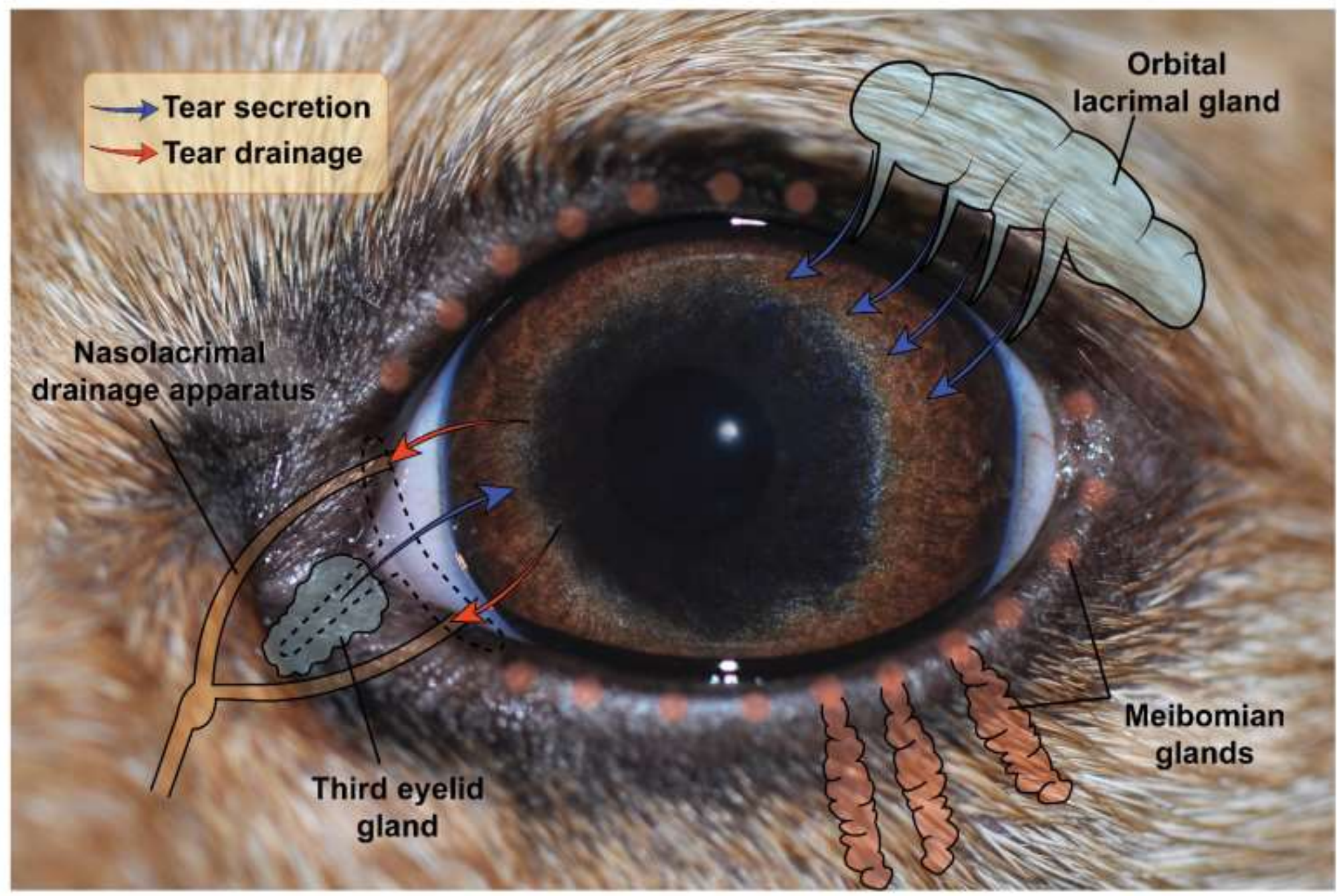


Figure 2. Diagram depicting the complexity of tear film dynamics and ocular surface physiology. Secretion of tear components, distribution of tears through blinking, and elimination through nasolacrimal drainage and evaporation must be precisely regulated to maintain homeostasis. Drug kinetics following topical eyedrop administration are impacted by key parameters highlighted in yellow, each being unique in different species. Adapted with permission from "Tsubota K, Tseng SCG, Nordlund ML. Anatomy and Physiology of the Ocular Surface In: Holland EJ,Mannis MJ, eds. Ocular Surface Disease Medical and Surgical Management. New York, NY: Springer New York, 2002;3-15”.

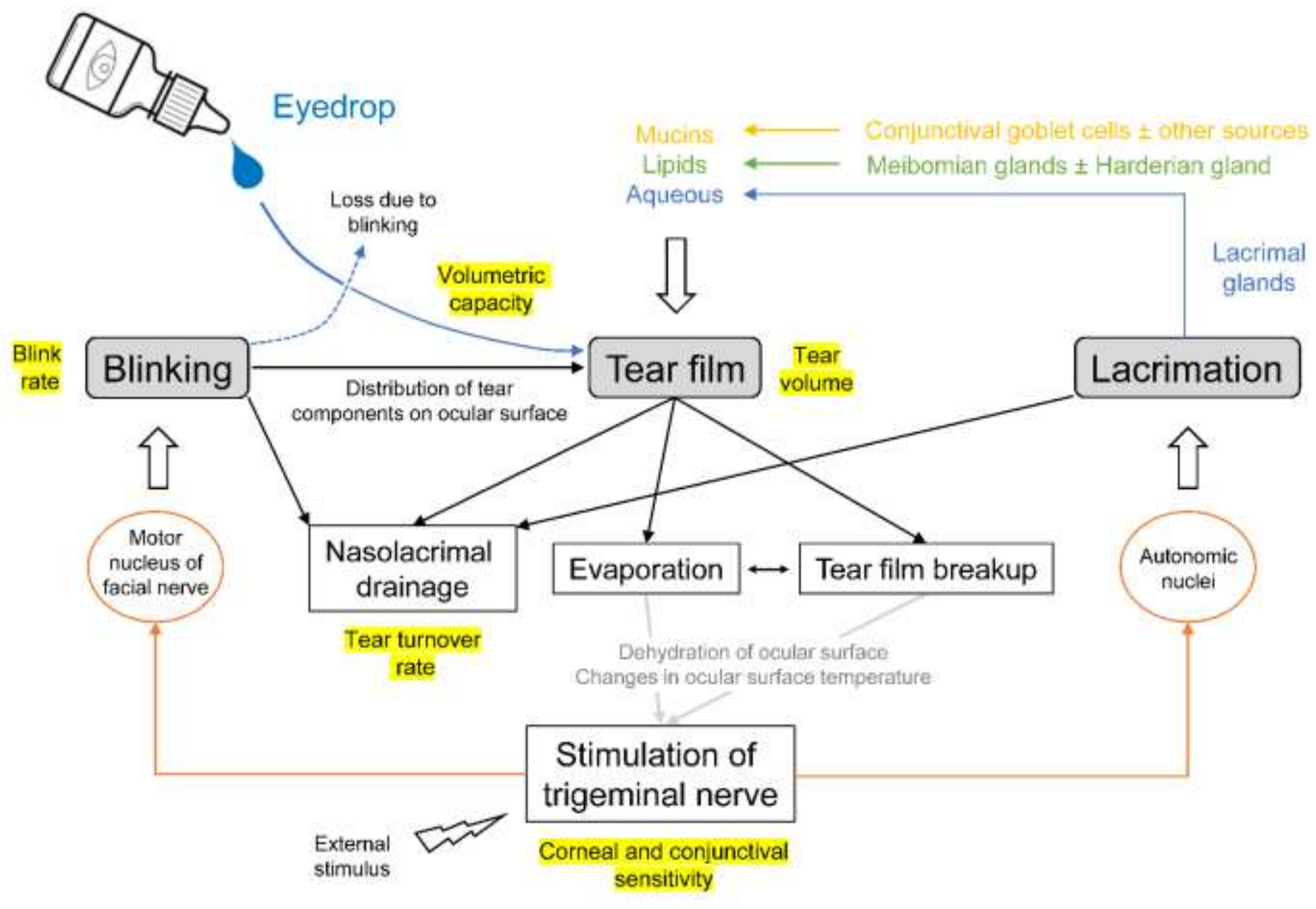


Figure 3. Tear collection in dogs using microcapillary glass tubes (a), Schirmer tear strips (b) or absorbent sponges (c).
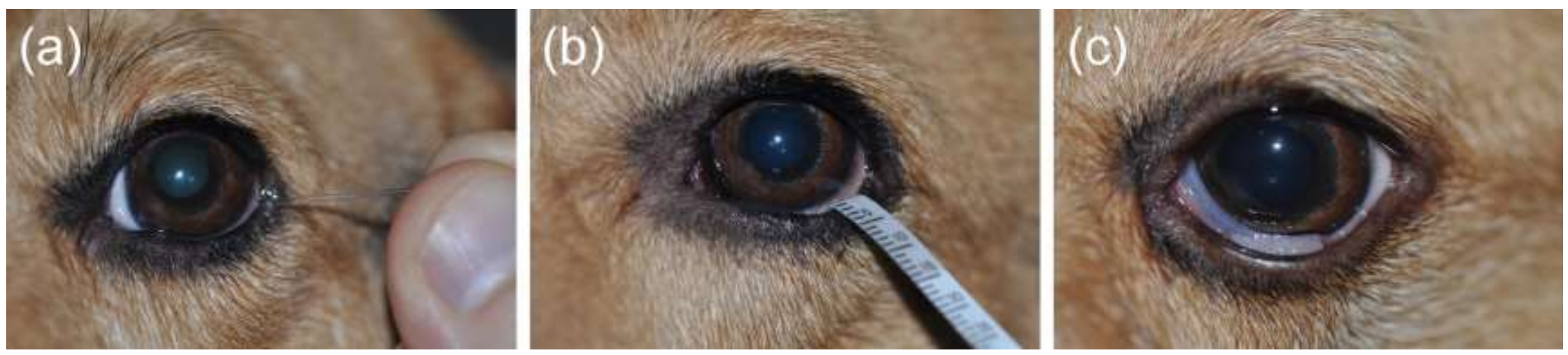
Figure 4. Step-by-step protocol to exact tear fluid from Schirmer strips for analytical purposes, using a combination of centrifugation and solvent wash. Centrifugation of wetted Schirmer strip (containing tear sample and internal standard) retrieves tear fluid in a large tube, while subsequent solvent elution washes residual content from the absorbent filter paper.

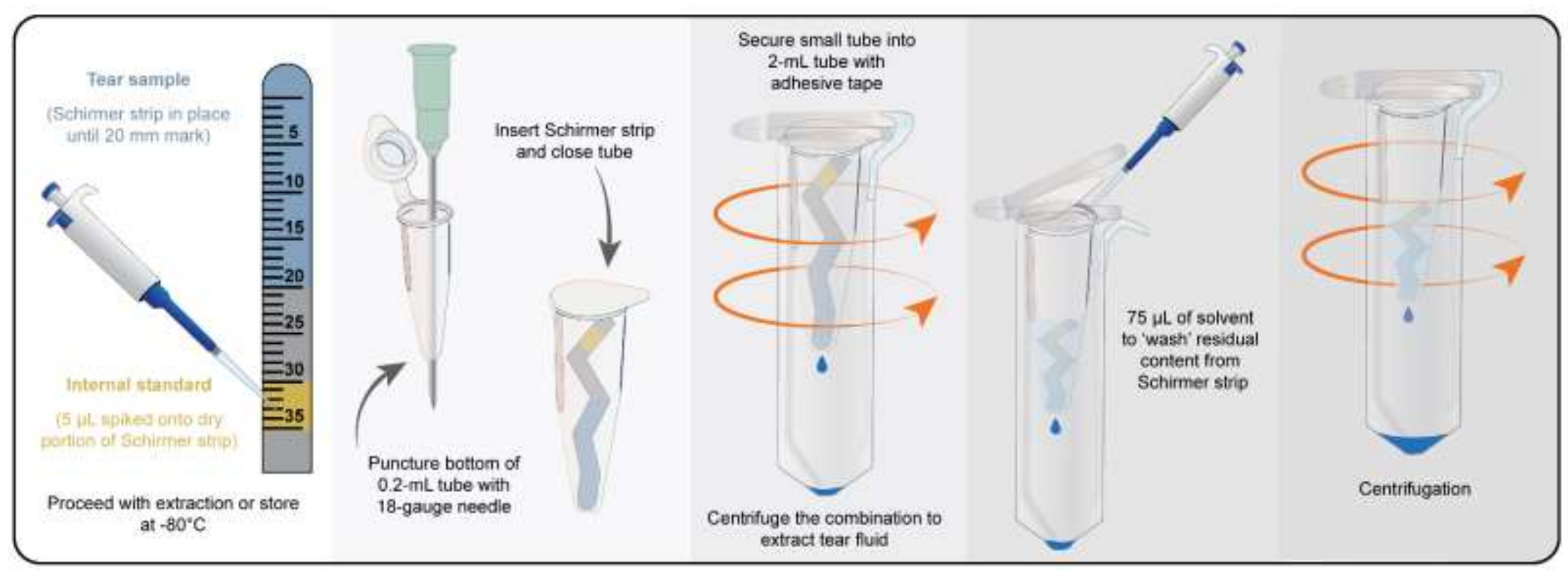


Figure 5. Representative clinical pictures of mild conjunctivitis (a), moderate conjunctivitis (b), and severe conjunctivitis (c) in dogs following topical administration of histamine at concentrations of $1 \mathrm{mg} / \mathrm{mL}, 10 \mathrm{mg} / \mathrm{mL}$ and $375 \mathrm{mg} / \mathrm{mL}$, respectively. Reprinted from "Sebbag L, Allbaugh RA, Weaver A, et al. Histamine-Induced Conjunctivitis and Breakdown of Blood-Tear Barrier in Dogs: A Model for Ocular Pharmacology and Therapeutics. Front Pharmacol 2019;10:752".
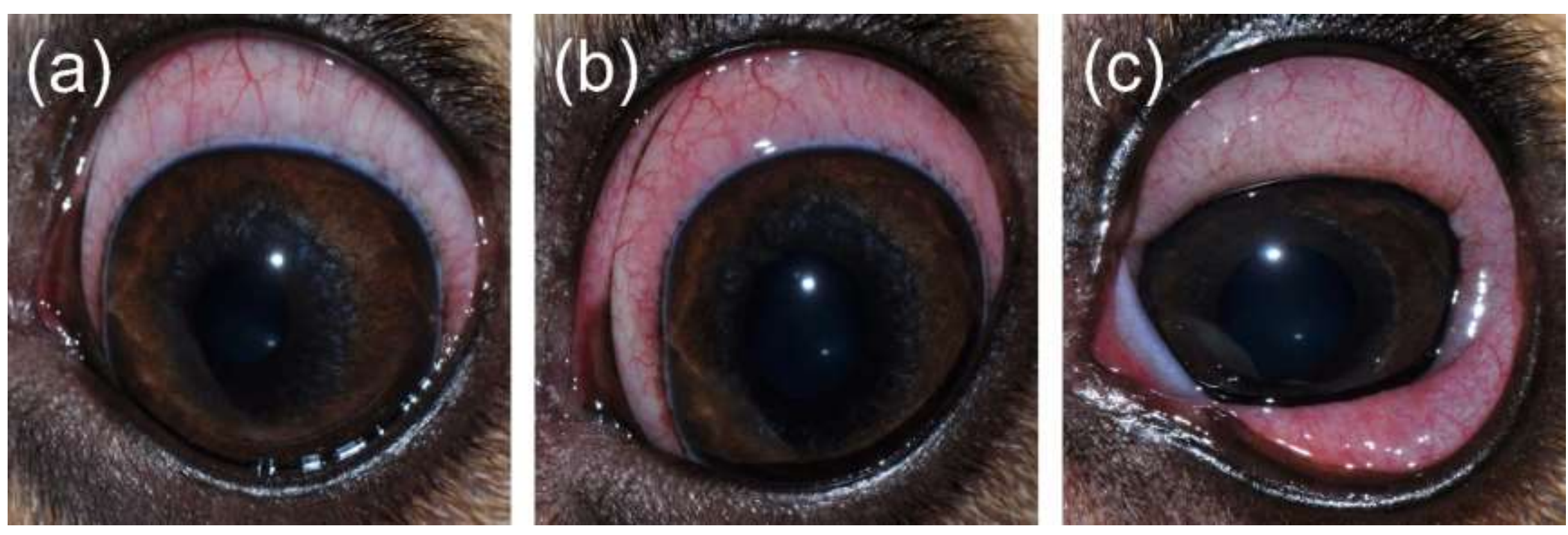
Figure 6. Graphical representation of the blood-tear barrier in the canine eye. The barrier is intact in healthy eyes (left) but is disrupted in diseased eyes (right), enhancing the flow of compounds (eg, albumin, xenobiotics) between the tear film and the blood compartments. Breakdown of the blood-tear barrier can have important clinical implications such as enhanced systemic absorption from greater conjunctival vascular permeability, or reduction in ocular drug bioavailability due to drug-albumin interactions in the tear film.

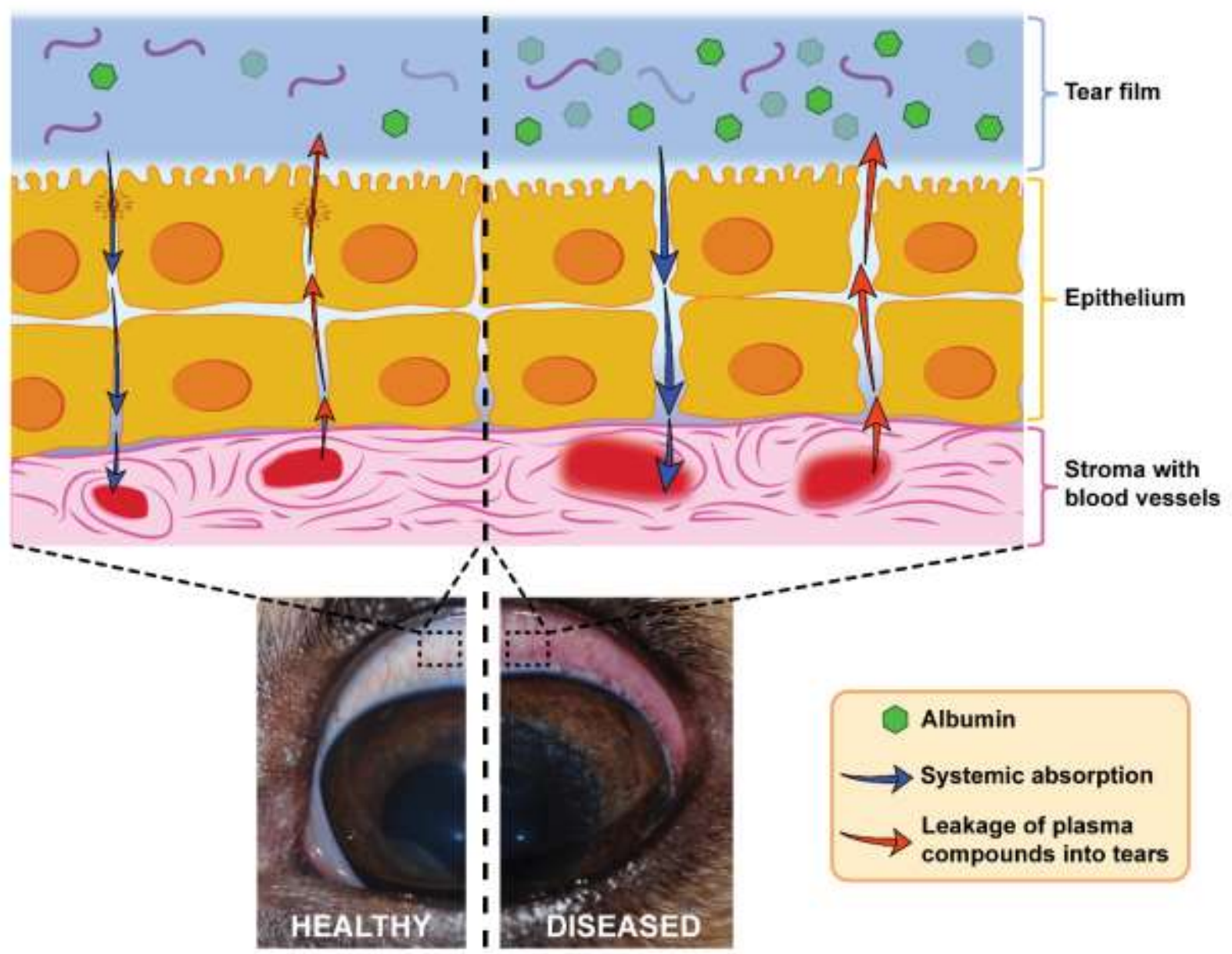




\section{AUTHOR BIOSKETCHES}

\section{Lionel Sebbag}

Dr. Sebbag obtained his Veterinary Medical Degree from the National Veterinary School of Toulouse. He then completed a rotating internship at Kansas State University before pursuing a residency in Comparative Ophthalmology at the University of California-Davis. Dr. Sebbag is a Diplomate of the American College of Veterinary Ophthalmologists (ACVO), and currently holds a position as an Assistant Professor in the Department of Veterinary Clinical Sciences (Ophthalmology service) at Iowa State University, while completing a Ph.D in Biomedical Sciences focused on pharmacology and ocular disease models. Dr. Sebbag clinical and research interests include ocular surface diseases, tear film biology and innovations in drug delivery to the eye. He received multiple academic awards and published over 40 articles in select biomedical journals.

\section{$\underline{\text { Jonathan P. Mochel }}$}

Dr. Mochel obtained his Veterinary Medical Degree from the National Veterinary School of Alfort. He completed his Doctorate studying Neurosciences in collaboration with the College de France, and received the Silver Medal from Paris XII for his work. Dr. Mochel holds a MS in Pharmacology and Pharmacokinetics and is a Diplomate of the European College of Veterinary Pharmacology and Toxicology (ECVPT). He completed his Ph.D at Leiden University, with a focus on the mathematical modeling of the renin-angiotensin system for cardiovascular diseases. He is a founder of the Animal Health Modeling \& Simulation Society which aims at promoting the dissemination of mathematical modeling in Veterinary Sciences. Dr. Mochel is an Associate Professor in the Department of Biomedical Sciences at Iowa State University (ISU) and the Chair of the Education and Residency Committee of the ECVPT. He is a Fellow of the American Academy of Veterinary Pharmacology and Therapeutics and the current Vice-President of the European Association of Veterinary Pharmacology and Toxicology. His research pertains to the analysis of clinical data obtained from spontaneous animal models of human diseases to bridge the knowledge gap between experimental models and patients. He has authored 70 peer-reviewed publications in select biomedical journals and was the 2019 recipient of the ISU Early Career Achievement in Research Award at the College of Veterinary Medicine. 


\section{REFERENCES}

1. Shah M, Cabrera-Ghayouri S, Christie LA, et al. Translational Preclinical Pharmacologic Disease Models for Ophthalmic Drug Development. Pharm Res 2019;36:58.

2. Maurice D. The effect of the low blink rate in rabbits on topical drug penetration. J Ocul Pharmacol Ther 1995; 11:297-304.

3. Takahashi K, Saishin Y, Mori K, et al. Topical nepafenac inhibits ocular neovascularization. Invest Ophthalmol Vis Sci 2003;44:409-415.

4. Hay M, Thomas DW, Craighead JL, et al. Clinical development success rates for investigational drugs. Nature Biotechnology 2014;32:40-51.

5. Harrison RK. Phase II and phase III failures: 2013-2015. Nature Reviews Drug Discovery 2016;15:817818.

6. Kol A, Arzi B, Athanasiou KA, et al. Companion animals: Translational scientist's new best friends. Sci Transl Med 2015;7:308ps321.

7. Garden OA, Volk SW, Mason NJ, et al. Companion animals in comparative oncology: One Medicine in action. Vet J 2018;240:6-13.

8. Partridge B, Rossmeisl JH. Companion animal models of neurological disease. J Neurosci Methods 2020;331:108484.

9. Shell JW. Pharmacokinetics of topically applied ophthalmic drugs. Surv Ophthalmol 1982;26:207-218.

10. Sakai T. Major ocular glands (harderian gland and lacrimal gland) of the musk shrew (Suncus murinus) with a review on the comparative anatomy and histology of the mammalian lacrimal glands. $J$ Morphol 1989;201:39-57.

11. Gilger BC, Abarca E, Salmon JH. Selection of Appropriate Animal Models in Ocular Research: Ocular Anatomy and Physiology of Common Animal Models In: Gilger BC, ed. Ocular Pharmacology and Toxicology. Totowa, NJ: Humana Press, 2014;7-32.

12. Sullivan DA, Hann LE, Yee L, et al. Age- and gender-related influence on the lacrimal gland and tears. Acta Ophthalmol (Copenh) 1990;68:188-194.

13. Saito A, Izumisawa Y, Yamashita K, et al. The effect of third eyelid gland removal on the ocular surface of dogs. Vet Ophthalmol 2001;4:13-18.

14. Park SA, Taylor KT, Zwingenberger AL, et al. Gross anatomy and morphometric evaluation of the canine lacrimal and third eyelid glands. Vet Ophthalmol 2016;19:230-236.

15. El-naseery N, El-behery E, El-Ghazali H, et al. The structural characterization of the lacrimal gland in the adult dog (Canis familiaris). Benha Veterinary Medical Journal 2016;31:106-116.

16. Murphy CJ, Samuelson DA, Pollock RVH. Chapter 21: The eye. Miller's anatomy of the dog 2013:746785.

17. Zwingenberger AL, Park SA, Murphy CJ. Computed tomographic imaging characteristics of the normal canine lacrimal glands. BMC Vet Res 2014;10:116.

18. Bulbul E, Yazici A, Yanik B, et al. Evaluation of Lacrimal Gland Dimensions and Volume in Turkish Population with Computed Tomography. J Clin Diagn Res 2016;10:TC06-08.

19. Lamagna B, Peruccio C, Guardascione A, et al. Conjunctival dacryops in two golden retrievers. Vet Ophthalmol 2012;15:194-199.

20. Conrady CD, Joos ZP, Patel BC. Review: The Lacrimal Gland and Its Role in Dry Eye. J Ophthalmol 2016;2016:7542929.

21. Kim EC, Doh SH, Chung SY, et al. Direct visualization of aqueous tear secretion from lacrimal gland. Acta Ophthalmol 2017;95:e314-e322.

22. Schechter JE, Warren DW, Mircheff AK. A lacrimal gland is a lacrimal gland, but rodent's and rabbit's are not human. Ocul Surf 2010;8:111-134.

23. Bergmanson JP, Doughty MJ, Blocker Y. The acinar and ductal organisation of the tarsal accessory lacrimal gland of Wolfring in rabbit eyelid. Exp Eye Res 1999;68:411-421.

24. Hirt R, Tektas OY, Carrington SD, et al. Comparative anatomy of the human and canine efferent tear duct system--impact of mucin MUC5AC on lacrimal drainage. Curr Eye Res 2012;37:961-970. 
25. Ali MJ, Rehorek SJ, Paulsen F. A major review on disorders of the animal lacrimal drainage systems: Evolutionary perspectives and comparisons with humans. Ann Anat 2019;224:102-112.

26. Burling K, Murphy CJ, Curiel JS, et al. Anatomy of the rabbit nasolacrimal duct and its clinical implications. Progress in veterinary \& comparative ophthalmology 1991;1:33-40.

27. Rehorek SJ, Holland JR, Johnson JL, et al. Development of the Lacrimal Apparatus in the Rabbit (Oryctolagus cuniculus) and Its Potential Role as an Animal Model for Humans. Anat Res Int 2011;2011:623186.

28. Paulsen FP, Föge M, Thale AB, et al. Animal model for the absorption of lipophilic substances from tear fluid by the epithelium of the nasolacrimal ducts. Invest Ophthalmol Vis Sci 2002;43:3137-3143.

29. Frame NJ, Burkat CN. Identifying an appropriate animal model for the nasolacrimal drainage system. Ophthalmic Plast Reconstr Surg 2009;25:354-358.

30. Arends G, Schramm U. The structure of the human semilunar plica at different stages of its development--a morphological and morphometric study. Ann Anat 2004;186:195-207.

31. Chae JJ, Shin YJ, Lee JD, et al. Nictitating membrane fixation improves stability of the contact lens on the animal corneal surface. PLoS One 2018;13:e0194795.

32. Stevenson W, Chen Y, Lee SM, et al. Extraorbital lacrimal gland excision: a reproducible model of severe aqueous tear-deficient dry eye disease. Cornea 2014;33:1336-1341.

33. Petznick A, Evans MD, Madigan MC, et al. A comparison of basal and eye-flush tears for the analysis of cat tear proteins. Acta Ophthalmol 2011;89:e75-81.

34. Saito A, Watanabe Y, Kotani T. Morphologic changes of the anterior corneal epithelium caused by third eyelid removal in dogs. Vet Ophthalmol 2004;7:113-119.

35. Leiva M, Pena Gimenez T. Diseases of the lacrimal system. Slatter's fundamentals of veterinary ophthalmology 6th ed Missouri: Elsevier 2017:186-212.

36. Paranjpe V, Phung L, Galor A. The Tear Film: Anatomy and Physiology In: Guidoboni G, Harris A,Sacco R, eds. Ocular Fluid Dynamics: Anatomy, Physiology, Imaging Techniques, and Mathematical Modeling. Cham: Springer International Publishing, 2019;329-345.

37. Milz S, Neufang J, Higashiyama I, et al. An immunohistochemical study of the extracellular matrix of the tarsal plate in the upper eyelid in human beings. J Anat 2005;206:37-45.

38. Prince JH, Diesem CD, Eglitis I, et al. Anatomy and histology of the eye and orbit in domestic animals: Springfield, Illinois: Charles C. Thomas. Oxford: Blackwell Scientific Publications., 1960.

39. Greiner JV, Glonek T, Korb DR, et al. Volume of the human and rabbit meibomian gland system. Adv Exp Med Biol 1998;438:339-343.

40. Sebbag L, Kirner NS, Allbaugh RA, et al. Kinetics of Fluorescein in Tear Film After Eye Drop Instillation in Beagle Dogs: Does Size Really Matter? Frontiers in Veterinary Science 2019;6:457.

41. Peiffer RL, Pohm-Thorsen L, Corcoran K. CHAPTER 19 - Models in Ophthalmology and Vision Research**Supported in part by a Grant from Research to Prevent Blindness and the North Carolina Lions Foundation In: Manning PJ, Ringler DH,Newcomer CE, eds. The Biology of the Laboratory Rabbit (Second Edition). San Diego: Academic Press, 1994;409-433.

42. Rajaei SM, Rafiee SM, Ghaffari MS, et al. Measurement of Tear Production in English Angora and Dutch Rabbits. J Am Assoc Lab Anim Sci 2016;55:221-223.

43. Qiu Y, Yang H, Lei B. Effects of three commonly used anesthetics on intraocular pressure in mouse. Curr Eye Res 2014;39:365-369.

44. Finlayson K, Lampe JF, Hintze S, et al. Facial Indicators of Positive Emotions in Rats. PLOS ONE 2016;11:e0166446.

45. Odigie AE, Ekeolu KO, Asemota DO, et al. Comparative non-metric and morphometric analyses of rats at residential halls of the University of Benin campus, Nigeria. J Infect Public Health 2018;11:412-417.

46. Lee HK, Woo IH, Kang B, et al. Meibography and Immunohistochemistric Structures in Animal Models. Journal of the Korean Ophthalmological Society 2018;59:9-16.

47. Moore CP, McHugh JB, Thorne JG, et al. Effect of cyclosporine on conjunctival mucin in a canine keratoconjunctivitis sicca model. Invest Ophthalmol Vis Sci 2001;42:653-659. 
48. Kang Y, Li S, Liu C, et al. A rabbit model for assessing symblepharon after alkali burn of the superior conjunctival sac. Sci Rep 2019;9:13857.

49. Jutley G, Carpenter D, Hau S, et al. Upper and lower conjunctival fornix depth in healthy white caucasian eyes: a method of objective assessment. Eye (Lond) 2016;30:1351-1358.

50. Watsky MA, Jablonski MM, Edelhauser HF. Comparison of conjunctival and corneal surface areas in rabbit and human. Curr Eye Res 1988;7:483-486.

51. Gipson IK, Tisdale AS. Visualization of conjunctival goblet cell actin cytoskeleton and mucin content in tissue whole mounts. Exp Eye Res 1997;65:407-415.

52. Moore CP, Wilsman NJ, Nordheim EV, et al. Density and distribution of canine conjunctival goblet cells. Invest Ophthalmol Vis Sci 1987;28:1925-1932.

53. Kessing SV. Mucous gland system of the conjunctiva. A quantitative normal anatomical study. Acta Ophthalmol (Copenh) 1968:Suppl 95:91+.

54. Vujković V, Mikac G, Kozomara R. Distribution and density of conjunctival goblet cells. Med Pregl 2002;55:195-200.

55. Umeda Y, Nakamura S, Fujiki K, et al. Distribution of goblet cells and MUC5AC mRNA in the canine nictitating membrane. Exp Eye Res 2010;91:721-726.

56. Doughty MJ. On the in vivo assessment of goblet cells of the human bulbar conjunctiva by confocal microscopy - A review. Cont Lens Anterior Eye 2020.

57. Kishishita H, Nakayasu K. Distribution of conjunctival goblet cells and observation of goblet cells after conjunctival autotransplantation in rabbits. Nippon Ganka Gakkai Zasshi 1996;100:433-442.

58. Doughty MJ. Scanning electron microscopy study of the tarsal and orbital conjunctival surfaces compared to peripheral corneal epithelium in pigmented rabbits. Doc Ophthalmol 1997;93:345-371.

59. Doughty MJ. A systematic assessment of goblet cell sampling of the bulbar conjunctiva by impression cytology. Exp Eye Res 2015;136:16-28.

60. Steven P, Gebert A. Conjunctiva-associated lymphoid tissue - current knowledge, animal models and experimental prospects. Ophthalmic Res 2009;42:2-8.

61. Chodosh J, Nordquist RE, Kennedy RC. Comparative anatomy of mammalian conjunctival lymphoid tissue: a putative mucosal immune site. Dev Comp Immunol 1998;22:621-630.

62. Sakimoto T, Shoji J, Inada N, et al. Histological study of conjunctiva-associated lymphoid tissue in mouse. Jpn J Ophthalmol 2002;46:364-369.

63. Giuliano EA, Moore CP, Phillips TE. Morphological evidence of M cells in healthy canine conjunctivaassociated lymphoid tissue. Graefes Arch Clin Exp Ophthalmol 2002;240:220-226.

64. Knop N, Knop E. Ultrastructural anatomy of CALT follicles in the rabbit reveals characteristics of Mcells, germinal centres and high endothelial venules. J Anat 2005;207:409-426.

65. Zhong X, Liu H, Pu A, et al. M cells are involved in pathogenesis of human contact lens-associated giant papillary conjunctivitis. Arch Immunol Ther Exp (Warsz) 2007;55:173-177.

66. Vézina M. Comparative Ocular Anatomy in Commonly Used Laboratory Animals In: Weir AB,Collins M, eds. Assessing Ocular Toxicology in Laboratory Animals. Totowa, NJ: Humana Press, 2013;1-21.

67. Marfurt C, Anokwute MC, Fetcko K, et al. Comparative Anatomy of the Mammalian Corneal Subbasal Nerve Plexus. Invest Ophthalmol Vis Sci 2019;60:4972-4984.

68. Reichard M, Hovakimyan M, Wree A, et al. Comparative in vivo confocal microscopical study of the cornea anatomy of different laboratory animals. Curr Eye Res 2010;35:1072-1080.

69. Babrauskienė V, Žymantienė J, Aniulienė A, et al. Comparative morphological evaluation of animal corneal parameters. Medycyna Weterynaryjna 2018;74:452-455.

70. Nautscher N, Bauer A, Steffl M, et al. Comparative morphological evaluation of domestic animal cornea. Vet Ophthalmol 2016;19:297-304.

71. Holloway CL. Changes with age in the eye of the dog and hog from birth to senility. 1969.

72. Heywood R. Some clinical observations on the eyes of Sprague-Dawley rats. Lab Anim 1973;7:19-27.

73. Hughes A. A schematic eye for the rat. Vision Res 1979;19:569-588.

74. Henriksson JT, McDermott AM, Bergmanson JP. Dimensions and morphology of the cornea in three strains of mice. Invest Ophthalmol Vis Sci 2009;50:3648-3654. 
75. Augusteyn RC, Nankivil D, Mohamed A, et al. Human ocular biometry. Exp Eye Res 2012;102:70-75. 76. Wang X, Dong J, Wu Q. Mean central corneal thickness and corneal power measurements in pigmented and white rabbits using Visante optical coherence tomography and ATLAS corneal topography. Vet Ophthalmol 2014;17:87-90.

77. Thomasy SM, Eaton JS, Timberlake MJ, et al. Species Differences in the Geometry of the Anterior Segment Differentially Affect Anterior Chamber Cell Scoring Systems in Laboratory Animals. J Ocul Pharmacol Ther 2016;32:28-37.

78. Strom AR, Cortés DE, Rasmussen CA, et al. In vivo evaluation of the cornea and conjunctiva of the normal laboratory beagle using time- and Fourier-domain optical coherence tomography and ultrasound pachymetry. Vet Ophthalmol 2016;19:50-56.

79. Li HF, Petroll WM, Møller-Pedersen T, et al. Epithelial and corneal thickness measurements by in vivo confocal microscopy through focusing (CMTF). Curr Eye Res 1997;16:214-221.

80. Schulz D, Iliev ME, Frueh BE, et al. In vivo pachymetry in normal eyes of rats, mice and rabbits with the optical low coherence reflectometer. Vision Res 2003;43:723-728.

81. Spoerl E, Mrochen M, Sliney D, et al. Safety of UVA-riboflavin cross-linking of the cornea. Cornea 2007;26:385-389.

82. MD M, J C, M C, et al. A comparative study of Bowman's layer in some mammals: Relationships with other constituent corneal structures. Eur J Anat 2002;6:133-139.

83. Ehlers N. Morphology and histochemistry of the corneal epithelium of mammals. Acta Anat (Basel) 1970;75:161-198.

84. Molon-Noblot SM, Duprat P. Anatomy of the Ocular Surfaces, Cornea, and Conjunctiva, Rat and Mouse In: Jones TC, Mohr U,Hunt RD, eds. Eye and Ear. Berlin, Heidelberg: Springer Berlin Heidelberg, 1991;3-16.

85. Filizay MC, Gökçınar NB, Şahinturk V, et al. Evaluation of Retinol Palmitate Treatment of Photokeratitis in Rat Eyes Exposed to Ultraviolet B Radiation. Evaluation 2019;4:55-61.

86. Thomasy SM, Raghunathan VK, Winkler M, et al. Elastic modulus and collagen organization of the rabbit cornea: epithelium to endothelium. Acta Biomater 2014;10:785-791.

87. Leonard BC, Cosert K, Winkler M, et al. Stromal Collagen Arrangement Correlates with Stiffness of the Canine Cornea. Bioengineering (Basel) 2020;7.

88. Huang J, Camras LJ, Yuan F. Mechanical analysis of rat trabecular meshwork. Soft Matter 2015;11:2857-2865.

89. Xu P, Londregan A, Rich C, et al. Changes in Epithelial and Stromal Corneal Stiffness Occur with Age and Obesity. Bioengineering 2020;7:14.

90. Duman R, Tok Çevik M, Görkem Çevik S, et al. Corneal endothelial cell density in healthy Caucasian population. Saudi J Ophthalmol 2016;30:236-239.

91. Zagon IS, Campbell AM, Sassani JW, et al. Spontaneous episodic decreased tear secretion in rats is related to opioidergic signaling pathways. Invest Ophthalmol Vis Sci 2012;53:3234-3240.

92. Wieser B, Tichy A, Nell B. Correlation between corneal sensitivity and quantity of reflex tearing in cows, horses, goats, sheep, dogs, cats, rabbits, and guinea pigs. Vet Ophthalmol 2013;16:251-262.

93. Reins RY, Courson J, Lema C, et al. MyD88 contribution to ocular surface homeostasis. PLoS One 2017;12:e182153.

94. McLaughlin PJ, Sassani JW, Titunick MB, et al. Efficacy and safety of a novel naltrexone treatment for dry eye in type 1 diabetes. BMC Ophthalmol 2019;19:35.

95. Bolzanni H, Oriá AP, Raposo ACS, et al. Aqueous tear assessment in dogs: Impact of cephalic conformation, inter-test correlations, and test-retest repeatability. Vet Ophthalmol 2020.

96. He J, Bazan HE. Neuroanatomy and Neurochemistry of Mouse Cornea. Invest Ophthalmol Vis Sci 2016;57:664-674.

97. Good KL, Maggs DJ, Hollingsworth SR, et al. Corneal sensitivity in dogs with diabetes mellitus. Am J Vet Res 2003;64:7-11.

98. Ledbetter EC, Marfurt CF, Dubielzig RR. Metaherpetic corneal disease in a dog associated with partial limbal stem cell deficiency and neurotrophic keratitis. Vet Ophthalmol 2013;16:282-288. 
99. Murphy CJ, Marfurt CF, McDermott A, et al. Spontaneous chronic corneal epithelial defects (SCCED) in dogs: clinical features, innervation, and effect of topical SP, with or without IGF-1. Invest Ophthalmol Vis Sci 2001;42:2252-2261.

100. Woo HM, Bentley E, Campbell SF, et al. Nerve growth factor and corneal wound healing in dogs. Exp Eye Res 2005;80:633-642.

101. Gilger BC, Reeves KA, Salmon JH. Ocular parameters related to drug delivery in the canine and equine eye: aqueous and vitreous humor volume and scleral surface area and thickness. Vet Ophthalmol 2005;8:265-269.

102. Vurgese S, Panda-Jonas S, Jonas JB. Scleral thickness in human eyes. PLoS One 2012;7:e29692.

103. Trier K, Olsen EB, Kobayashi T, et al. Biochemical and ultrastructural changes in rabbit sclera after treatment with 7-methylxanthine, theobromine, acetazolamide, or L-ornithine. $\mathrm{Br} J$ Ophthalmol 1999;83:1370-1375.

104. Pazos M, Yang H, Gardiner SK, et al. Rat optic nerve head anatomy within 3D histomorphometric reconstructions of normal control eyes. Exp Eye Res 2015;139:1-12.

105. Myers KM, Cone FE, Quigley HA, et al. The in vitro inflation response of mouse sclera. Exp Eye Res 2010;91:866-875.

106. Stern ME, Gao J, Siemasko KF, et al. The role of the lacrimal functional unit in the pathophysiology of dry eye. Exp Eye Res 2004;78:409-416.

107. Tomlinson A, Khanal S. Assessment of tear film dynamics: quantification approach. Ocul Surf 2005;3:81-95.

108. Garaszczuk IK, Montes Mico R, Iskander DR, et al. The tear turnover and tear clearance tests - a review. Expert Rev Med Devices 2018;15:219-229.

109. Mishima S, Gasset A, Klyce SD, et al. Determination of tear volume and tear flow. Invest Ophthalmol 1966;5:264-276.

110. van Best JA, Benitez del Castillo JM, Coulangeon LM. Measurement of basal tear turnover using a standardized protocol. European concerted action on ocular fluorometry. Graefes Arch Clin Exp Ophthalmol 1995;233:1-7.

111. Sebbag L, Allbaugh RA, Wehrman RF, et al. Fluorophotometric Assessment of Tear Volume and Turnover Rate in Healthy Dogs and Cats. J Ocul Pharmacol Ther 2019;35:497-502.

112. Chrai SS, Patton TF, Mehta A, et al. Lacrimal and instilled fluid dynamics in rabbit eyes. J Pharm Sci 1973;62:1112-1121.

113. Yoon KC, De Paiva CS, Qi H, et al. Desiccating environmental stress exacerbates autoimmune lacrimal keratoconjunctivitis in non-obese diabetic mice. J Autoimmun 2008;30:212-221.

114. Prabhasawat P, Tseng SC. Frequent association of delayed tear clearance in ocular irritation. $\mathrm{Br} J$ Ophthalmol 1998;82:666-675.

115. Shimizu A, Yokoi N, Nishida K, et al. [Fluorophotometric measurement of tear volume and tear turnover rate in human eyes]. Nippon Ganka Gakkai Zasshi 1993;97:1047-1052.

116. Whittaker AL, Williams DL. Evaluation of Lacrimation Characteristics in Clinically Normal New Zealand White Rabbits by Using the Schirmer Tear Test I. J Am Assoc Lab Anim Sci 2015;54:783-787.

117. Sullivan DA, Allansmith MR. Hormonal modulation of tear volume in the rat. Experimental Eye Research 1986;42:131-139.

118. McClellan AJ, Volpe EA, Zhang X, et al. Ocular surface disease and dacryoadenitis in aging C57BL/6 mice. Am J Pathol 2014;184:631-643.

119. King-Smith PE, Fink BA, Hill RM, et al. The thickness of the tear film. Curr Eye Res 2004;29:357368.

120. Purslow C, Wolffsohn JS. Ocular surface temperature: a review. Eye Contact Lens 2005;31:117-123. 121. Carrington SD, Bedford PGC, Guillon JP, et al. Polarized light biomicroscopic observations on the pre-corneal tear film. 1. The normal tear film of the dog. Journal of Small Animal Practice 1987;28:605622.

122. Bentivoglio AR, Bressman SB, Cassetta E, et al. Analysis of blink rate patterns in normal subjects. Mov Disord 1997;12:1028-1034. 
123. Korb DR, Greiner JV, Glonek T, et al. Human and Rabbit Lipid Layer and Interference Pattern Observations In: Sullivan DA, Dartt DA,Meneray MA, eds. Lacrimal Gland, Tear Film, and Dry Eye Syndromes 2: Basic Science and Clinical Relevance. Boston, MA: Springer US, 1998;305-308.

124. Kaminer J, Powers AS, Horn KG, et al. Characterizing the spontaneous blink generator: an animal model. J Neurosci 2011;31:11256-11267.

125. Kilic S, Kulualp K. Efficacy of Several Therapeutic Agents in a Murine Model of Dry Eye Syndrome. Comp Med 2016;66:112-118.

126. Sassa T, Tadaki M, Kiyonari H, et al. Very long-chain tear film lipids produced by fatty acid elongase ELOVL1 prevent dry eye disease in mice. The FASEB Journal 2018;32:2966-2978.

127. MISHIMA S, MAURICE DM. The oily layer of the tear film and evaporation from the corneal surface. Exp Eye Res 1961;1:39-45.

128. Dartt DA. Neural regulation of lacrimal gland secretory processes: relevance in dry eye diseases. Prog Retin Eye Res 2009;28:155-177.

129. Butovich IA, Lu H, McMahon A, et al. Toward an animal model of the human tear film: biochemical comparison of the mouse, canine, rabbit, and human meibomian lipidomes. Invest Ophthalmol Vis Sci 2012;53:6881-6896.

130. Inomata T, Iwagami M, Hiratsuka Y, et al. Maximum blink interval is associated with tear film breakup time: A new simple, screening test for dry eye disease. Scientific Reports 2018;8:13443.

131. Wei XE, Markoulli M, Zhao Z, et al. Tear film break-up time in rabbits. Clin Exp Optom 2013;96:7075.

132. Van Ooteghem MM. Factors Influencing the Retention of Ophthalmic Solutions on the Eye Surface. Ophthalmic Drug Delivery 1987;7-17.

133. Zaki I, Fitzgerald P, Hardy JG, et al. A comparison of the effect of viscosity on the precorneal residence of solutions in rabbit and man. J Pharm Pharmacol 1986;38:463-466.

134. Aihara M, Lindsey JD, Weinreb RN. Reduction of intraocular pressure in mouse eyes treated with latanoprost. Invest Ophthalmol Vis Sci 2002;43:146-150.

135. Linn CL, Webster SE, Webster MK. Eye Drops for Delivery of Bioactive Compounds and BrdU to Stimulate Proliferation and Label Mitotically Active Cells in the Adult Rodent Retina. Bio Protoc 2018;8. 136. Davies NM. Biopharmaceutical considerations in topical ocular drug delivery. Clin Exp Pharmacol Physiol 2000;27:558-562.

137. Oriá AP, Rebouças MF, Martins Filho E, et al. Photography-based method for assessing fluorescein clearance test in dogs. BMC Vet Res 2018;14:269.

138. Chrai SS, Makoid MC, Eriksen SP, et al. Drop size and initial dosing frequency problems of topically applied ophthalmic drugs. J Pharm Sci 1974;63:333-338.

139. Zeng M, Shen J, Liu Y, et al. The HIF-1 antagonist acriflavine: visualization in retina and suppression of ocular neovascularization. J Mol Med (Berl) 2017;95:417-429.

140. You IC, Li Y, Jin R, et al. Comparison of $0.1 \%, 0.18 \%$, and $0.3 \%$ Hyaluronic Acid Eye Drops in the Treatment of Experimental Dry Eye. J Ocul Pharmacol Ther 2018;34:557-564.

141. Pillion DJ, Bartlett JD, Meezan E, et al. Systemic absorption of insulin delivered topically to the rat eye. Invest Ophthalmol Vis Sci 1991;32:3021-3027.

142. Dartt DA, Willcox MD. Complexity of the tear film: importance in homeostasis and dysfunction during disease. Exp Eye Res 2013;117:1-3.

143. Sebbag L, McDowell EM, Hepner PM, et al. Effect of tear collection on lacrimal total protein content in dogs and cats: a comparison between Schirmer strips and ophthalmic sponges. BMC Vet Res 2018;14:61. 144. Yu V, Bhattacharya D, Webster A, et al. Clusterin from human clinical tear samples: Positive correlation between tear concentration and Schirmer strip test results. Ocul Surf 2018;16:478-486.

145. Roberts S, Erickson O. Dog tear secretion and tear proteins. Journal of Small Animal Practice 1968;3:1-5.

146. Kaswan RL, Fullard RJ. Components in normal dog tears and tears from dogs with KCS treated with cyclosporin. Fourth International Symposium 1994;265. 
147. Hemsley S, Cole N, Canfield P, et al. Protein microanalysis of animal tears. Research in Veterinary Science 2000;68:207-209.

148. Redl B. Human tear lipocalin. Biochimica et Biophysica Acta (BBA) - Protein Structure and Molecular Enzymology 2000;1482:241-248.

149. Winiarczyk M, Winiarczyk D, Banach T, et al. Dog Tear Film Proteome In-Depth Analysis. PLoS One 2015;10:e0144242.

150. de Freitas Campos C, Cole N, Van Dyk D, et al. Proteomic analysis of dog tears for potential cancer markers. Res Vet Sci 2008;85:349-352.

151. Wei XE. Biochemical studies of the tear film in humans and rabbits. School of Optometry and Vision Science: The University of New South Wales, Sydney, Australia, 2012.

152. Mantelli F, Argüeso P. Functions of ocular surface mucins in health and disease. Curr Opin Allergy Clin Immunol 2008;8:477-483.

153. Leonard BC, Yañez-Soto B, Raghunathan VK, et al. Species variation and spatial differences in mucin expression from corneal epithelial cells. Exp Eye Res 2016;152:43-48.

154. Royle L, Matthews E, Corfield A, et al. Glycan structures of ocular surface mucins in man, rabbit and dog display species differences. Glycoconj J 2008;25:763-773.

155. Butovich IA, Borowiak AM, Eule JC. Comparative HPLC-MS analysis of canine and human meibomian lipidomes: many similarities, a few differences. Sci Rep 2011;1:24.

156. Hendrix DV, Cox SK. Pharmacokinetics of topically applied ciprofloxacin in tears of mesocephalic and brachycephalic dogs. Vet Ophthalmol 2008;11:7-10.

157. Grumetto L, Cennamo G, Del Prete A, et al. Pharmacokinetics of cetirizine in tear fluid after a single oral dose. Clin Pharmacokinet 2002;41:525-531.

158. Sebbag L, Thomasy SM, Woodward AP, et al. Pharmacokinetic modeling of penciclovir and BRL42359 in the plasma and tears of healthy cats to optimize dosage recommendations for oral administration of famciclovir. Am J Vet Res 2016;77:833-845.

159. Sebbag L, Showman L, McDowell EM, et al. Impact of Flow Rate, Collection Devices, and Extraction Methods on Tear Concentrations Following Oral Administration of Doxycycline in Dogs and Cats. J Ocul Pharmacol Ther 2018;34:452-459.

160. Sebbag L, Yan Y, Smith JS, et al. Tear Fluid Pharmacokinetics Following Oral Prednisone Administration in Dogs With and Without Conjunctivitis. J Ocul Pharmacol Ther 2019;35:341-349.

161. Green-Church KB, Nichols KK, Kleinholz NM, et al. Investigation of the human tear film proteome using multiple proteomic approaches. Mol Vis 2008;14:456-470.

162. Zhou L, Zhao SZ, Koh SK, et al. In-depth analysis of the human tear proteome. J Proteomics 2012;75:3877-3885.

163. Li B, Sheng M, Li J, et al. Tear proteomic analysis of Sjögren syndrome patients with dry eye syndrome by two-dimensional-nano-liquid chromatography coupled with tandem mass spectrometry. Sci Rep 2014;4:5772.

164. Jung JH, Ji YW, Hwang HS, et al. Proteomic analysis of human lacrimal and tear fluid in dry eye disease. Sci Rep 2017;7:13363.

165. Huang Z, Du CX, Pan XD. The use of in-strip digestion for fast proteomic analysis on tear fluid from dry eye patients. PLoS One 2018;13:e0200702.

166. Nättinen J, Aapola U, Jylhä A, et al. Comparison of capillary and Schirmer strip tear fluid sampling methods using SWATH-MS proteomics approach. Translational Vision Science \& Technology 2020;9:1616.

167. Lam SM, Tong L, Duan X, et al. Extensive characterization of human tear fluid collected using different techniques unravels the presence of novel lipid amphiphiles. J Lipid Res 2014;55:289-298.

168. Cicalini I, Rossi C, Pieragostino D, et al. Integrated Lipidomics and Metabolomics Analysis of Tears in Multiple Sclerosis: An Insight into Diagnostic Potential of Lacrimal Fluid. Int J Mol Sci 2019;20.

169. von Thun Und Hohenstein-Blaul N, Funke S, Grus FH. Tears as a source of biomarkers for ocular and systemic diseases. Exp Eye Res 2013;117:126-137. 
170. Pieragostino D, D'Alessandro M, di Ioia M, et al. Unraveling the molecular repertoire of tears as a source of biomarkers: beyond ocular diseases. Proteomics Clin Appl 2015;9:169-186.

171. Hagan S, Martin E, Enríquez-de-Salamanca A. Tear fluid biomarkers in ocular and systemic disease: potential use for predictive, preventive and personalised medicine. EPMA J 2016;7:15.

172. Ngo W, Chen J, Panthi S, et al. Comparison of Collection Methods for the Measure of Human Meibum and Tear Film-Derived Lipids Using Mass Spectrometry. Curr Eye Res 2018;43:1244-1252.

173. Lee CH, Yeo A, Tae Im Kim MD, et al. Comparison of the Effectiveness between Sampling Methods for Protein Analysis of Tear Fluids. J Korean Ophthalmol Soc 2015;56:1677-1683.

174. Guyette N, Williams L, Tran MT, et al. Comparison of low-abundance biomarker levels in capillarycollected nonstimulated tears and washout tears of aqueous-deficient and normal patients. Invest Ophthalmol Vis Sci 2013;54:3729-3737.

175. Sitaramamma T, Shivaji S, Rao GN. HPLC analysis of closed, open, and reflex eye tear proteins. Indian J Ophthalmol 1998;46:239-245.

176. Posa A, Bräuer L, Schicht M, et al. Schirmer strip vs. capillary tube method: non-invasive methods of obtaining proteins from tear fluid. Ann Anat 2013;195:137-142.

177. Hanstock HG, Walsh NP, Edwards JP, et al. Tear Fluid SIgA as a Noninvasive Biomarker of Mucosal Immunity and Common Cold Risk. Med Sci Sports Exerc 2016;48:569-577.

178. Hanstock HG, Edwards JP, Walsh NP. Tear Lactoferrin and Lysozyme as Clinically Relevant Biomarkers of Mucosal Immune Competence. Front Immunol 2019;10:1178.

179. Esmaeelpour M, Cai J, Watts P, et al. Tear sample collection using cellulose acetate absorbent filters. Ophthalmic Physiol Opt 2008;28:577-583.

180. Markoulli M, Papas E, Petznick A, et al. Validation of the flush method as an alternative to basal or reflex tear collection. Curr Eye Res 2011;36:198-207.

181. López-Cisternas J, Castillo-Díaz J, Traipe-Castro L, et al. Use of polyurethane minisponges to collect human tear fluid. Cornea 2006;25:312-318.

182. Runström G, Mann A, Tighe B. The fall and rise of tear albumin levels: a multifactorial phenomenon. Ocul Surf 2013;11:165-180.

183. Van Agtmaal EJ, ThÖRig L, Van Haeringen NJ. Comparative Protein Patterns in Tears of Several Species In: Peeters H, ed. Protides of the Biological Fluids: Elsevier, 1985;395-397.

184. Wei XE, Markoulli M, Millar TJ, et al. Divalent cations in tears, and their influence on tear film stability in humans and rabbits. Invest Ophthalmol Vis Sci 2012;53:3280-3285.

185. Jones DT, Monroy D, Pflugfelder SC. A novel method of tear collection: comparison of glass capillary micropipettes with porous polyester rods. Cornea 1997;16:450-458.

186. Farias E, Yasunaga KL, Peixoto RVR, et al. Comparison of two methods of tear sampling for protein quantification by Bradford method. Pesquisa Veterinária Brasileira 2013;33:261-264.

187. Davidson HJ, Blanchard GL, Montgomery PC. Comparisons of tear proteins in the cow, horse, dog and rabbit. Adv Exp Med Biol 1994;350:331-334.

188. Brantman KR. Tear film VEGF in dogs with vascularizing corneal disease. Biomedical and Veterinary Sciences. Blacksburg, VA: Virginia Polytechnic Institute and State University, 2013;79.

189. Martinez PS, Storey ES, Pucheu-Haston CM. Survey of cytokines in normal canine tears by multiplex analysis: A pilot study. Vet Immunol Immunopathol 2018;201:38-42.

190. Thörig L, van Agtmaal EJ, Glasius E, et al. Comparison of tears and lacrimal gland fluid in the rabbit and guinea pig. Curr Eye Res 1985;4:913-920.

191. Small D, Hevy J, Tang-Liu D. Comparison of tear sampling techniques for pharmacokinetics analysis: ofloxacin concentrations in rabbit tears after sampling with schirmer tear strips, capillary tubes, or surgical sponges. J Ocul Pharmacol Ther 2000;16:439-446.

192. Coursey TG, Henriksson JT, Marcano DC, et al. Dexamethasone nanowafer as an effective therapy for dry eye disease. J Control Release 2015;213:168-174.

193. Shah M, Edman MC, Reddy Janga S, et al. Rapamycin Eye Drops Suppress Lacrimal Gland Inflammation In a Murine Model of Sjögren's Syndrome. Invest Ophthalmol Vis Sci 2017;58:372-385. 
194. Thörig L, van Haeringen NJ, Wijngaards G. Comparison of enzymes of tears, lacrimal gland fluid and lacrimal gland tissue in the rat. Experimental Eye Research 1984;38:605-609.

195. Ahn S, Eom Y, Kang B, et al. Effects of Menthol-Containing Artificial Tears on Tear Stimulation and Ocular Surface Integrity in Normal and Dry Eye Rat Models. Curr Eye Res 2018;43:580-587.

196. Oriá AP, Raposo ACS, Araújo NLLC, et al. Tear ferning test in healthy dogs. Vet Ophthalmol 2018;21:391-398.

197. Dumortier G, Chaumeil JC. Lachrymal determinations: methods and updates on biopharmaceutical and clinical applications. Ophthalmic Res 2004;36:183-194.

198. Karn RC, Laukaitis CM. Comparative Proteomics of Mouse Tears and Saliva: Evidence from Large Protein Families for Functional Adaptation. Proteomes 2015;3:283-297.

199. Rentka A, Koroskenyi K, Harsfalvi J, et al. Evaluation of commonly used tear sampling methods and their relevance in subsequent biochemical analysis. Ann Clin Biochem 2017;54:521-529.

200. Berta A. Collection of tear samples with or without stimulation. Am J Ophthalmol 1983;96:115-116. 201. Kaswan RL, Salisbury MA, Ward DA. Spontaneous canine keratoconjunctivitis sicca. A useful model for human keratoconjunctivitis sicca: treatment with cyclosporine eye drops. Arch Ophthalmol 1989; 107:1210-1216.

202. Lemp MA, Bron AJ, Baudouin C, et al. Tear osmolarity in the diagnosis and management of dry eye disease. Am J Ophthalmol 2011;151:792-798.e791.

203. Sebbag L, Pesavento PA, Carrasco SE, et al. Feline dry eye syndrome of presumed neurogenic origin: a case report. JFMS Open Rep 2018;4:2055116917746786.

204. Sebbag L, Uhl LK, Schneider B, et al. Investigation of Schirmer tear test-1 for measurement of tear production in cats in various environmental settings and with different test durations. J Am Vet Med Assoc 2020;256:681-686.

205. Leonard BC, Stewart KA, Shaw GC, et al. Comprehensive Clinical, Diagnostic, and Advanced Imaging Characterization of the Ocular Surface in Spontaneous Aqueous Deficient Dry Eye Disease in Dogs. Cornea 2019.

206. Uhl LK, Saito A, Iwashita H, et al. Clinical features of cats with aqueous tear deficiency: a retrospective case series of 10 patients (17 eyes). J Feline Med Surg 2019;21:944-950.

207. Denisin AK, Karns K, Herr AE. Post-collection processing of Schirmer strip-collected human tear fluid impacts protein content. Analyst 2012;137:5088-5096.

208. VanDerMeid KR, Su SP, Krenzer KL, et al. A method to extract cytokines and matrix metalloproteinases from Schirmer strips and analyze using Luminex. Mol Vis 2011;17:1056-1063.

209. Sebbag L, Moody LM, Allbaugh RA, et al. Nerve growth factor in dogs: Assessment of two immunoassays and selected ocular parameters following a nicergoline challenge per os. Vet Ophthalmol 2019.

210. Balafas E, Katsila T, Melissa P, et al. A Noninvasive Ocular (Tear) Sampling Method for Genetic Ascertainment of Transgenic Mice and Research Ethics Innovation. OMICS 2019;23:312-317.

211. Gaal V, Mark L, Kiss P, et al. Investigation of the Effects of PACAP on the Composition of Tear and Endolymph Proteins. Journal of Molecular Neuroscience 2008;36:321-329.

212. Sebbag L, Allbaugh RA, Weaver A, et al. Histamine-Induced Conjunctivitis and Breakdown of BloodTear Barrier in Dogs: A Model for Ocular Pharmacology and Therapeutics. Front Pharmacol 2019;10:752. 213. Collins SP, Labelle AL, Dirikolu L, et al. Tear film concentrations of doxycycline following oral administration in ophthalmologically normal dogs. $J$ Am Vet Med Assoc 2016;249:508-514.

214. Sebbag L, Harrington DM, Mochel JP. Tear fluid collection in dogs and cats using ophthalmic sponges. Vet Ophthalmol 2018;21:249-254.

215. Beckwith-Cohen B, Elad D, Bdolah-Abram T, et al. Comparison of tear pH in dogs, horses, and cattle. Am J Vet Res 2014;75:494-499.

216. Inic-Kanada A, Nussbaumer A, Montanaro J, et al. Comparison of ophthalmic sponges and extraction buffers for quantifying cytokine profiles in tears using Luminex technology. Mol Vis 2012;18:2717-2725. 217. Sia RK, Ryan DS, Howard RS, et al. Non-stimulated tear sample collection using polyvinyl alcohol (PVA) foam and polyester wick. Int J Ophthalmol Clin Res 2016;3:048. 
218. Quah JH, Tong L, Barbier S. Patient acceptability of tear collection in the primary healthcare setting. Optom Vis Sci 2014;91:452-458.

219. Li S, Sack R, Vijmasi T, et al. Antibody protein array analysis of the tear film cytokines. Optom Vis Sci 2008;85:653-660.

220. Stuchell RN, Feldman JJ, Farris RL, et al. The effect of collection technique on tear composition. Invest Ophthalmol Vis Sci 1984;25:374-377.

221. Bertram M, Mochel J, Allbaugh R, et al. Influence of Schirmer strip wetness on volume absorbed, volume recovered, and total protein content in canine tears. ISU CVM Research Day. Ames, IA, 2019.

222. Monk CS, Jeong SY, Gibson DJ, et al. The presence of minocycline in the tear film of normal horses following oral administration and its anticollagenase activity. Vet Ophthalmol 2018;21:58-65.

223. Lerch M, Allbaugh RA, Sebbag L, et al. Paper spray high-resolution accurate mass spectrometry for quantitation of voriconazole in equine tears. Anal Bioanal Chem 2019;411:5187-5196.

224. Page L, Mochel J, Allbaugh R, et al. Impact of diurnal variability and tear collection method on total protein content and albumin levels in canine tears. ISU CVM Research Day 2019.

225. Hawkins EC, Murphy CJ. Inconsistencies in the absorptive capacities of Schirmer tear test strips. $J$ Am Vet Med Assoc 1986;188:511-513.

226. García-Porta N, Mann A, Sáez-Martínez V, et al. The potential influence of Schirmer strip variables on dry eye disease characterisation, and on tear collection and analysis. Cont Lens Anterior Eye 2018;41:4753.

227. Dionne K, Redfern RL, Nichols JJ, et al. Analysis of tear inflammatory mediators: A comparison between the microarray and Luminex methods. Mol Vis 2016;22:177-188.

228. Sapan CV, Lundblad RL, Price NC. Colorimetric protein assay techniques. Biotechnol Appl Biochem 1999;29 ( Pt 2):99-108.

229. Sebbag L, Moody LM, Mochel JP. Albumin Levels in Tear Film Modulate the Bioavailability of Medically-Relevant Topical Drugs. Front Pharmacol 2019;10:1560.

230. Hirosawa M, Sambe T, Uchida N, et al. Determination of nonsteroidal anti-inflammatory drugs in human tear and plasma samples using ultra-fast liquid chromatography-tandem mass spectrometry. Jpn J Ophthalmol 2015;59:364-371.

231. Maggio F. Ocular surface disease in dogs part 1: aetiopathogenesis and clinical signs. Companion Animal 2019;24:240-245.

232. Holve DL, Mundwiler KE, Pritt SL. Incidence of spontaneous ocular lesions in laboratory rabbits. Comp Med 2011;61:436-440.

233. Bedard KM. Ocular Surface Disease of Rabbits. Vet Clin North Am Exot Anim Pract 2019;22:1-14.

234. Hubert MF, Gerin G, Durand-Cavagna G. Spontaneous ophthalmic lesions in young Swiss mice. $L a b$ Anim Sci 1999;49:232-240.

235. Moore BA, Roux MJ, Sebbag L, et al. A Population Study of Common Ocular Abnormalities in C57BL/6N rd8 Mice. Invest Ophthalmol Vis Sci 2018;59:2252-2261.

236. Monk C. Ocular Surface Disease in Rodents (Guinea Pigs, Mice, Rats, Chinchillas). Vet Clin North Am Exot Anim Pract 2019;22:15-26.

237. Craig JP, Nelson JD, Azar DT, et al. TFOS DEWS II Report Executive Summary. Ocul Surf 2017; 15:802-812.

238. Barabino S, Dana MR. Animal models of dry eye: a critical assessment of opportunities and limitations. Invest Ophthalmol Vis Sci 2004;45:1641-1646.

239. Barabino S, Chen W, Dana MR. Tear film and ocular surface tests in animal models of dry eye: uses and limitations. Exp Eye Res 2004;79:613-621.

240. Stern ME, Pflugfelder SC. What We Have Learned From Animal Models of Dry Eye. Int Ophthalmol Clin 2017;57:109-118.

241. Dong ZY, Ying M, Zheng J, et al. Evaluation of a rat meibomian gland dysfunction model induced by closure of meibomian gland orifices. Int J Ophthalmol 2018;11:1077-1083.

242. Burgalassi S, Panichi L, Chetoni P, et al. Development of a simple dry eye model in the albino rabbit and evaluation of some tear substitutes. Ophthalmic Res 1999;31:229-235. 
243. Li N, Deng X, Gao Y, et al. Establishment of the mild, moderate and severe dry eye models using three methods in rabbits. BMC Ophthalmology 2013;13:50.

244. Dursun D, Wang M, Monroy D, et al. A mouse model of keratoconjunctivitis sicca. Invest Ophthalmol Vis Sci 2002;43:632-638.

245. Viñas M, Maggio F, D'Anna N, et al. Meibomian gland dysfunction (MGD), as diagnosed by noncontact infrared Meibography, in dogs with ocular surface disorders (OSD): a retrospective study. BMC Vet Res 2019;15:443.

246. Murphy CJ, Bentley E, Miller PE, et al. The pharmacologic assessment of a novel lymphocyte function-associated antigen-1 antagonist (SAR 1118) for the treatment of keratoconjunctivitis sicca in dogs. Invest Ophthalmol Vis Sci 2011;52:3174-3180.

247. Dupuis P, Prokopich CL, Hynes A, et al. A contemporary look at allergic conjunctivitis. Allergy Asthma Clin Immunol 2020;16:5.

248. Bundoc VG, Keane-Myers A. Animal models of ocular allergy. Curr Opin Allergy Clin Immunol 2003;3:375-379.

249. Groneberg DA, Bielory L, Fischer A, et al. Animal models of allergic and inflammatory conjunctivitis. Allergy 2003;58:1101-1113.

250. Lourenço-Martins AM, Delgado E, Neto I, et al. Allergic conjunctivitis and conjunctival provocation tests in atopic dogs. Vet Ophthalmol 2011;14:248-256.

251. Bean AG, Baker ML, Stewart CR, et al. Studying immunity to zoonotic diseases in the natural host keeping it real. Nat Rev Immunol 2013;13:851-861.

252. Marquart ME. Animal models of bacterial keratitis. J Biomed Biotechnol 2011;2011:680642.

253. Pennington MR, Ledbetter EC, Van de Walle GR. New Paradigms for the Study of Ocular Alphaherpesvirus Infections: Insights into the Use of Non-Traditional Host Model Systems. Viruses 2017;9. 254. Ledbetter EC, Dubovi EJ, Kim SG, et al. Experimental primary ocular canine herpesvirus-1 infection in adult dogs. Am J Vet Res 2009;70:513-521.

255. Ollivier FJ. Bacterial corneal diseases in dogs and cats. Clin Tech Small Anim Pract 2003;18:193-198. 256. Bartimote C, Foster J, Watson S. The spectrum of Microbial Keratitis: An updated review. The Open Ophthalmology Journal 2019;13.

257. Somayaji R, Priyantha MA, Rubin JE, et al. Human infections due to Staphylococcus pseudintermedius, an emerging zoonosis of canine origin: report of 24 cases. Diagn Microbiol Infect Dis 2016;85:471-476.

258. Thomasy SM, Cortes DE, Hoehn AL, et al. In Vivo Imaging of Corneal Endothelial Dystrophy in Boston Terriers: A Spontaneous, Canine Model for Fuchs' Endothelial Corneal Dystrophy. Invest Ophthalmol Vis Sci 2016;57:OCT495-503.

259. Sanchez RF, Daniels JT. Mini-Review: Limbal Stem Cells Deficiency in Companion Animals: Time to Give Something Back? Curr Eye Res 2016;41:425-432.

260. Dreyfus J, Schobert CS, Dubielzig RR. Superficial corneal squamous cell carcinoma occurring in dogs with chronic keratitis. Vet Ophthalmol 2011;14:161-168.

261. Sebbag L, Crabtree EE, Sapienza JS, et al. Corneal hypoesthesia, aqueous tear deficiency, and neurotrophic keratopathy following micropulse transscleral cyclophotocoagulation in dogs. Vet Ophthalmol 2019.

262. Azari AA, Barney NP. Conjunctivitis: a systematic review of diagnosis and treatment. JAMA 2013;310:1721-1729.

263. Maggs DJ. Diseases of the Conjunctiva In: Maggs DJ, Miller PE,Ofri R, eds. Slatter's fundamentals of veterinary ophthalmology. 6th ed. St Louis, Missouri: Saunders, 2018.

264. Soler E, Mochel J, Allbaugh R, et al. Impact of acute conjunctivitis on tear film dynamics, quantity and quality in healthy Beagle dogs. The 50th Annual Scientific Meeting of the American College of Veterinary Ophthalmologists, . Maui, Hawaii, 2019;E28-E80.

265. Zavaro A, Samra Z, Baryishak R, et al. Proteins in tears from healthy and diseased eyes. Doc Ophthalmol 1980;50:185-199. 
266. Janssen PT, Van Bijsterveld OP. Blood-tear barrier and tear fluid composition. The Precorneal Tear Film in Health, Disease and Contact Lens Wear, Holly FJ, editor Lubbock, TX, Dry Eye Institute 1986:471475.

267. Li K, Liu X, Chen Z, et al. Quantification of tear proteins and sPLA2-IIa alteration in patients with allergic conjunctivitis. Mol Vis 2010;16:2084-2091.

268. Mikkelson TJ, Chrai SS, Robinson JR. Altered bioavailability of drugs in the eye due to drug-protein interaction. J Pharm Sci 1973;62:1648-1653.

269. Takahashi A, Sumi T, Tada K, et al. Evaluation of histamine-induced conjunctival oedema in guinea pigs by means of image analysis. Br J Ophthalmol 2010;94:1657-1661.

270. Terhaar M, Allbaugh R, Mochel J, et al. Serum albumin and total protein concentration in the tear film of horses with healthy or diseased eyes, 2019.

271. van Bijsterveld OP, Janssen PT. The effect of calcium dobesilate on albumin leakage of the conjunctival vessels. Curr Eye Res 1981;1:425-430.

272. Guo Y, Ramachandran C, Satpathy M, et al. Histamine-induced myosin light chain phosphorylation breaks down the barrier integrity of cultured corneal epithelial cells. Pharm Res 2007;24:1824-1833.

273. de Wolf FA, Brett GM. Ligand-binding proteins: their potential for application in systems for controlled delivery and uptake of ligands. Pharmacol Rev 2000;52:207-236.

274. Dalhoff A. Seventy-Five Years of Research on Protein Binding. Antimicrob Agents Chemother 2018;62.

275. Prausnitz MR, Noonan JS. Permeability of cornea, sclera, and conjunctiva: a literature analysis for drug delivery to the eye. J Pharm Sci 1998;87:1479-1488.

276. Ramsay E, Ruponen M, Picardat T, et al. Impact of Chemical Structure on Conjunctival Drug Permeability: Adopting Porcine Conjunctiva and Cassette Dosing for Construction of In Silico Model. $J$ Pharm Sci 2017;106:2463-2471.

277. Gronkiewicz KM, Giuliano EA, Kuroki K, et al. Development of a novel in vivo corneal fibrosis model in the dog. Exp Eye Res 2016;143:75-88.

278. Robaei D, Watson S. Corneal blindness: a global problem. Clin Exp Ophthalmol 2014;42:213-214. 279. Stepp MA, Zieske JD, Trinkaus-Randall V, et al. Wounding the cornea to learn how it heals. Exp Eye Res 2014;121:178-193.

280. Proietto LR, Whitley RD, Brooks DE, et al. Development and Assessment of a Novel Canine Ex Vivo Corneal Model. Curr Eye Res 2017;42:813-821.

281. Berkowski WM, Gibson DJ, Craft SL, et al. Development and assessment of a novel ex vivo corneal culture technique involving an agarose-based dome scaffold for use as a model of in vivo corneal wound healing in dogs and rabbits. Am J Vet Res 2020;81:47-57.

282. Berkowski WM, Gibson DJ, Seo S, et al. Assessment of Topical Therapies for Improving the Optical Clarity Following Stromal Wounding in a Novel Ex Vivo Canine Cornea Model. Invest Ophthalmol Vis Sci 2018;59:5509-5521.

283. Harman RM, Bussche L, Ledbetter EC, et al. Establishment and Characterization of an Air-Liquid Canine Corneal Organ Culture Model To Study Acute Herpes Keratitis. Journal of Virology 2014;88:13669.

284. Chrai SS, Robinson JR. Ocular evaluation of methylcellulose vehicle in albino rabbits. J Pharm Sci 1974;63:1218-1223.

285. Beauchamp G. Half-Blind to the Risk of Predation. Frontiers in Ecology and Evolution 2017;5.

286. Owen GR, Brooks AC, James O, et al. A novel in vivo rabbit model that mimics human dosing to determine the distribution of antibiotics in ocular tissues. J Ocul Pharmacol Ther 2007;23:335-342.

287. Seo J, Byun WY, Alisafaei F, et al. Multiscale reverse engineering of the human ocular surface. Nat Med 2019;25:1310-1318.

288. Schneider B, Balbas-Martinez V, Jergens AE, et al. Model-Based Reverse Translation Between Veterinary and Human Medicine: The One Health Initiative. CPT Pharmacometrics Syst Pharmacol 2018;7:65-68. 
289. Kühnel W. Morphology of the Harderian Gland in the Rabbit. A Short Review In: Webb SM, Hoffman RA, Puig-Domingo ML, et al., eds. Harderian Glands: Porphyrin Metabolism, Behavioral and Endocrine Effects. Berlin, Heidelberg: Springer Berlin Heidelberg, 1992;109-125.

290. Ma H, Chen Y, Cai X, et al. Effect of aging in periocular appearances by comparison of anthropometry between early and middle adulthoods in Chinese Han population. J Plast Reconstr Aesthet Surg 2019;72:2002-2008.

291. Packer RM, Hendricks A, Burn CC. Impact of facial conformation on canine health: corneal ulceration. PLoS One 2015;10:e0123827.

292. Bron AJ, Benjamin L, Snibson GR. Meibomian gland disease. Classification and grading of lid changes. Eye (Lond) 1991;5 ( Pt 4):395-411.

293. Wang J, Call M, Mongan M, et al. Meibomian gland morphogenesis requires developmental eyelid closure and lid fusion. Ocul Surf 2017;15:704-712.

294. Last JA, Thomasy SM, Croasdale CR, et al. Compliance profile of the human cornea as measured by atomic force microscopy. Micron 2012;43:1293-1298.

295. Silver DM, Csutak A. Human Eye Dimensions for Pressure-Volume Relations. Investigative Ophthalmology \& Visual Science 2010;51:5019-5019.

296. Atsumi I, Kurata M, Sakaki H. Comparative study on ocular anatomical features among rabbits, beagle dogs and cynomolgus monkeys. Animal Eye Research 2013;32:35-41.

297. Zhou X, Xie J, Shen M, et al. Biometric measurement of the mouse eye using optical coherence tomography with focal plane advancement. Vision Res 2008;48:1137-1143.

298. Vogel B, Wagner H, Gmoser J, et al. Touch-free measurement of body temperature using close-up thermography of the ocular surface. MethodsX 2016;3:407-416.

299. Efron N, Young G, Brennan NA. Ocular surface temperature. Curr Eye Res 1989;8:901-906.

300. Biondi F, Dornbusch PT, Sampaio M, et al. Infrared ocular thermography in dogs with and without keratoconjunctivitis sicca. Vet Ophthalmol 2015;18:28-34.

301. Tran CH, Routledge C, Miller J, et al. Examination of murine tear film. Invest Ophthalmol Vis Sci 2003;44:3520-3525.

302. Chen HB, Yamabayashi S, Ou B, et al. Structure and composition of rat precorneal tear film. A study by an in vivo cryofixation. Invest Ophthalmol Vis Sci 1997;38:381-387.

303. Fukuoka S, Arita R. Increase in tear film lipid layer thickness after instillation of 3\% diquafosol ophthalmic solution in healthy human eyes. Ocul Surf 2017;15:730-735.

304. Kimball SH, King-Smith PE, Nichols JJ. Evidence for the Major Contribution of Evaporation to Tear Film Thinning between Blinks. Investigative Ophthalmology \& Visual Science 2010;51:6294-6297.

305. Paschides CA, Kitsios G, Karakostas KX, et al. Evaluation of tear break-up time, Schirmer's-I test and rose bengal staining as confirmatory tests for keratoconjunctivitis sicca. Clin Exp Rheumatol 1989;7:155157.

306. Kurtul BE, Özer PA, Aydinli MS. The association of vitamin D deficiency with tear break-up time and Schirmer testing in non-Sjögren dry eye. Eye (Lond) 2015;29:1081-1084.

307. Saito A, Kotani T. Estimation of lacrimal level and testing methods on normal beagles. Vet Ophthalmol 2001;4:7-11.

308. Miyasaka K, Kazama Y, Iwashita H, et al. A novel strip meniscometry method for measuring aqueous tear volume in dogs: Clinical correlations with the Schirmer tear and phenol red thread tests. Vet Ophthalmol 2019.

309. Biricik HS, Oğuz H, Sindak N, et al. Evaluation of the Schirmer and phenol red thread tests for measuring tear secretion in rabbits. Vet Rec 2005;156:485-487.

310. Senchyna M, Wax MB. Quantitative assessment of tear production: A review of methods and utility in dry eye drug discovery. J Ocul Biol Dis Infor 2008;1:1-6.

311. De Silva MEH, Hill LJ, Downie LE, et al. The Effects of Aging on Corneal and Ocular Surface Homeostasis in Mice. Invest Ophthalmol Vis Sci 2019;60:2705-2715.

312. Marques DL, Alves M, Modulo CM, et al. Lacrimal osmolarity and ocular surface in experimental model of dry eye caused by toxicity. Revista Brasileira de Oftalmologia 2015;74:68. 
313. Doughty MJ. Tear Film Stability and Tear Break Up Time (TBUT) in Laboratory Rabbits-A Systematic Review. Current Eye Research 2018;43:961-964.

314. Sebbag L, Park SA, Kass PH, et al. Assessment of tear film osmolarity using the TearLab( ${ }^{\mathrm{TM}}$ ) osmometer in normal dogs and dogs with keratoconjunctivitis sicca. Vet Ophthalmol 2017;20:357-364.

315. Honkanen R, Huang W, Huang L, et al. A New Rabbit Model of Chronic Dry Eye Disease Induced by Complete Surgical Dacryoadenectomy. Curr Eye Res 2019;44:863-872.

316. Chen FS, Maurice DM. The $\mathrm{pH}$ in the precorneal tear film and under a contact lens measured with a fluorescent probe. Experimental Eye Research 1990;50:251-259.

317. Ruiz-Ederra J, Levin MH, Verkman AS. In Situ Fluorescence Measurement of Tear Film [Na+], [K+], [Cl-], and $\mathrm{pH}$ in Mice Shows Marked Hypertonicity in Aquaporin-5 Deficiency. Investigative Ophthalmology \& Visual Science 2009;50:2132-2138.

318. Prydal JI, Muir MG, Dilly PN. Comparison of tear film thickness in three species determined by the glass fibre method and confocal microscopy. Eye (Lond) 1993;7 ( Pt 3):472-475.

319. Boonstra A, Kijlstra A. The identification of transferrin, an iron-binding protein in rabbit tears. Exp Eye Res 1984;38:561-567.

320. Zhou L, Beuerman RW, Barathi A, et al. Analysis of rabbit tear proteins by high-pressure liquid chromatography/electrospray ionization mass spectrometry. Rapid Commun Mass Spectrom 2003;17:401412.

321. Seamon V, Vellala K, Zylberberg C, et al. Sex hormone regulation of tear lipocalin in the rabbit lacrimal gland. Exp Eye Res 2008;87:184-190.

322. Kelly KE. Clinical study of canine tear lacritin as a treatment for dry eye. 2016.

323. Zhang FD, Hao ZQ, Gao W, et al. Effect of topical $0.05 \%$ cyclosporine A on the tear protein lacritin in a rat model of dry eye. Int J Ophthalmol 2019;12:189-193.

324. Ginel PJ, Novales M, García M, et al. Immunoglobulins in stimulated tears of dogs. Am J Vet Res 1993;54:1060-1063.

325. Fullard RJ, Kaswan RM, Bounous DI, et al. Tear protein profiles vs. clinical characteristics of untreated and cyclosporine-treated canine KCS. J Am Optom Assoc 1995;66:397-404.

326. Sullivan DA, Allansmith MR. Source of IgA in tears of rats. Immunology 1984;53:791-799.

327. Bodelier VMW, van Haeringen NJ, Klaver PSY. Species differences in tears; Comparative investigation in the chimpanzee (Pan troglodytes). Primates 1993;34:77-84.

328. Tei M, Spurr-Michaud SJ, Tisdale AS, et al. Vitamin A deficiency alters the expression of mucin genes by the rat ocular surface epithelium. Invest Ophthalmol Vis Sci 2000;41:82-88.

329. Shirai K, Saika S. Ocular surface mucins and local inflammation--studies in genetically modified mouse lines. BMC Ophthalmol 2015;15 Suppl 1:154.

330. Harvey DJ, Tiffany JM, Duerden JM, et al. Identification by combined gas chromatography-mass spectrometry of constituent long-chain fatty acids and alcohols from the meibomian glands of the rat and a comparison with human meibomian lipids. J Chromatogr 1987;414:253-263. 